\title{
Mobile sensor platforms: categorisation and research applications in precision farming
}

\author{
C. W. Zecha, J. Link, and W. Claupein \\ University of Hohenheim, Institute of Crop Science, Department of Agronomy (340a), Fruwirthstr. 23, \\ 70599 Stuttgart, Germany
}

Correspondence to: C. W. Zecha (christoph.zecha@uni-hohenheim.de)

Received: 22 January 2013 - Revised: 5 April 2013 - Accepted: 8 April 2013 - Published: 14 May 2013

\begin{abstract}
The usage of mobile sensor platforms arose in research a few decades ago. Since the beginning of satellite sensing, measurement principles and analysing methods have become widely implemented for aerial and ground vehicles. Mainly in Europe, the United States and Australia, sensor platforms in precision farming are used for surveying, monitoring and scouting tasks. This review gives an overview of available sensor platforms used in recent agricultural and related research projects. A general categorisation tree for platforms is outlined in this work. Working in manual, automatic or autonomous ways, these ground platforms and unmanned aircraft systems (UAS) with an agricultural scope are presented with their sensor equipment and the possible architectural models. Thanks to advances in highly powerful electronics, smaller devices mounted on platforms have become economically feasible for many applications. Designed to work automatically or autonomously, they will be able to interact in intelligent swarms. Sensor platforms can fulfil the need for developing, testing and optimising new applications in precision farming like weed control or pest management. Furthermore, commercial suppliers of platform hardware used in sensing tasks are listed.
\end{abstract}

\section{Introduction}

The first stationary industrial robot was developed by George Devol and Joseph F. Engelberger in the early 1960s for the production line of an automotive manufacturer (Engelberger, 1999). Due to constant, structured and predictable environmental indoor working conditions, the control and management of them can be done in an automated way. Based on this knowledge, operational outdoor platforms emerged in research: manually driven, partly automatic, completely autonomous mobile sensor platforms or robots. Their implementation with the same safety and accuracy for field tasks is more challenging due to the rough and changing conditions. One important criteria for outdoor operations is a precise position referencing of a vehicle or robot. The civilian use of the global positioning system (GPS) and the switched off selective availability (SA) in the year 2000 by the US Department of Defence (Langley, 1997) enabled a serviceable position referencing outdoors. With differential GPS (DGPS) and the Russian Global Navigation Satellite Sys- tem (GLONASS), accuracy increased to less than $5 \mathrm{~m}$. This capability also allowed for more applications in agriculture. In the early 1990s, technologies for precision farming (PF) were introduced to the market. PF was initially used as a synonym for automatic steering systems (Auernhammer, 2001). Meanwhile the main focus of PF has shifted and the aim of current $\mathrm{PF}$ applications is to apply the input factors at the right time, in the right amount at the right place (Khosla, 2010). Against this background practical applicability for PF technology remains linked to high-tech agriculture using machine guidance and site-specific seeding, fertilization plant protection with variable rates of seeds, fertilizer or pesticides (Seelan et al., 2003). Efficient use of resources, protection of the environment and documentation of applied management prescriptions are the reasons for PF application (Haboudane et al., 2002). Through new developments in sensor techniques and computer electronics, their reliability increased significantly. It became easier to adapt approaches from related research fields into the practical application of PF and thus to improve management decisions in terms of nutrient 
application. Nearly all manufacturers of agricultural machinery offer sensor systems for their field vehicles, subsequent data processing and subsequent application planning. Noncomparable data, conversion problems derived from various manufactures using different sources, as well as the lack of appropriate decision support systems (DSS) has impeded the full adoption of PF in the past (McBratney et al., 2005).

During the last decade, the main focus lay on development of sensors able to guide farmers through site-specific nutrient management. Most sensors are based on optical technology, e.g. interpretation of spectral signatures to identify the nutrient status in plants and to apply online directly the right amount of fertilizer. Recognized heterogeneity in fields due to differences in crop colour, yield amount or weed spots can be precisely georeferenced and considered for future management decisions (Zhang et al., 2002).

Most commercially available sensors are based on single sensor signals. In some cases, this leads to misinterpretation of the truth for variability or heterogeneity (Zillmann et al., 2006). In order to strengthen the reliability of implemented sensor signals, the idea of using a combination of sensors is gaining popularity. To merge all sensor data for analysis, the fusion of information is a necessary requisite. Dasarathy (2001) used "information fusion" as a general term for data fusion approaches. Furthermore, Adamchuk et al. (2010) described PF as "a perfect field where sensor fusion concepts are essential". The integration of multiple sensors for decision-making in agriculture is already utilised by researchers and developers; however, costs of sensor systems have to decrease for a faster adoption on farm sites (Adamchuk et al., 2010). Implementing low-cost consumer (e.g. digital cameras) or industrial components (e.g. robust software routines for feature recognition) will enable farmers to economically gain access to this sensing technology.

This paper aims to cover three questions: (1) How can mobile sensor platforms be categorised in general? (2) Which mobile sensor platforms are already in use or in development? (3) For what tasks are existing mobile sensor platforms able to be applied to?

In this publication an overview will be given about available manual, automatic and autonomous mobile sensor platforms used in actual agricultural and closely related science projects. Section 2 presents a general categorisation for mobile sensor platforms used for data collection. Furthermore, Sect. 2 focuses on architecture models implementing fusion algorithms on actual platforms and robots fulfilling these requisites. Section 3 delves into detail regarding the sensor platforms used in agricultural research topics. Ground and aerial vehicles for detection of soil and plant characteristics are described and an outlook to robot swarms will be given. Section 4 discusses uncertainties, strengths and limitations of the presented sensor systems. This literature overview is concluded by Sect. 5 .

\section{Platform categorisation}

The term "platform" has multiple meanings. This paper focuses on the technological term where it is defined as a "carrier system for payload, as a combination of hardware and software architecture frameworks" (Merriam-Webster Inc., 2013) e.g. "the combination of a particular computer and a particular operating system" (Princeton University, 2013). Several categories of platforms can be differentiated as displayed in Fig. 1. The particular modules are described below in the following text.

\subsection{Research area}

Innovations in mobile sensor platforms for PF originate from various research areas. Amongst them, the military sector, with a high capital backing. Therefore, highly advanced solutions can be achieved quickly. With a certain time delay, the civil sector also benefits from these developments. Most technology first applied in military operations spills over to the civil sector, e.g. GPS, internet or satellite imagery. Most clients of this new technology are from industry and the surveying business, having sold a high number of units. Even though aquaculture for food production increases every year, with huge application areas, agriculture and forestry have increasing demands for technology, e.g. for weed management, but these markets are slow to emerge (Frost et al., 1996; McBratney et al., 2005).

\subsection{Systematic concept}

The systematic concepts include a range of tasks and consist of mapping, monitoring, scouting and applying. The different research areas require diverse systematic concepts. The military mainly needs applications for scouting tasks to observe terrain and make tactical decisions. In the area of agriculture, at the moment, monitoring and scouting sensor platforms are mainly being implemented (Griepentrog et al., 2010; Ruckelshausen, 2012).

\subsection{Approach}

The systematic concept defines whether the approach must be online or if an offline strategy would be sufficient for the special task. An offline (mapping) method is based on stored data. It is characterized by separate steps: (1) measurement/detection, (2) calculation, and (3) application (Ruckelshausen, 2012) and provides the possibility to combine different sources of information (Maidl et al., 2004; Link et al., 2007). An online (sensor) method takes into account the measured data in real time for the decision calculation. This is done by a task controller, a terminal or a computer system and is considered directly for the on-the-go application. In combination with DGPS the data of the application can be mapped for data analysis and traceability. Due to the 


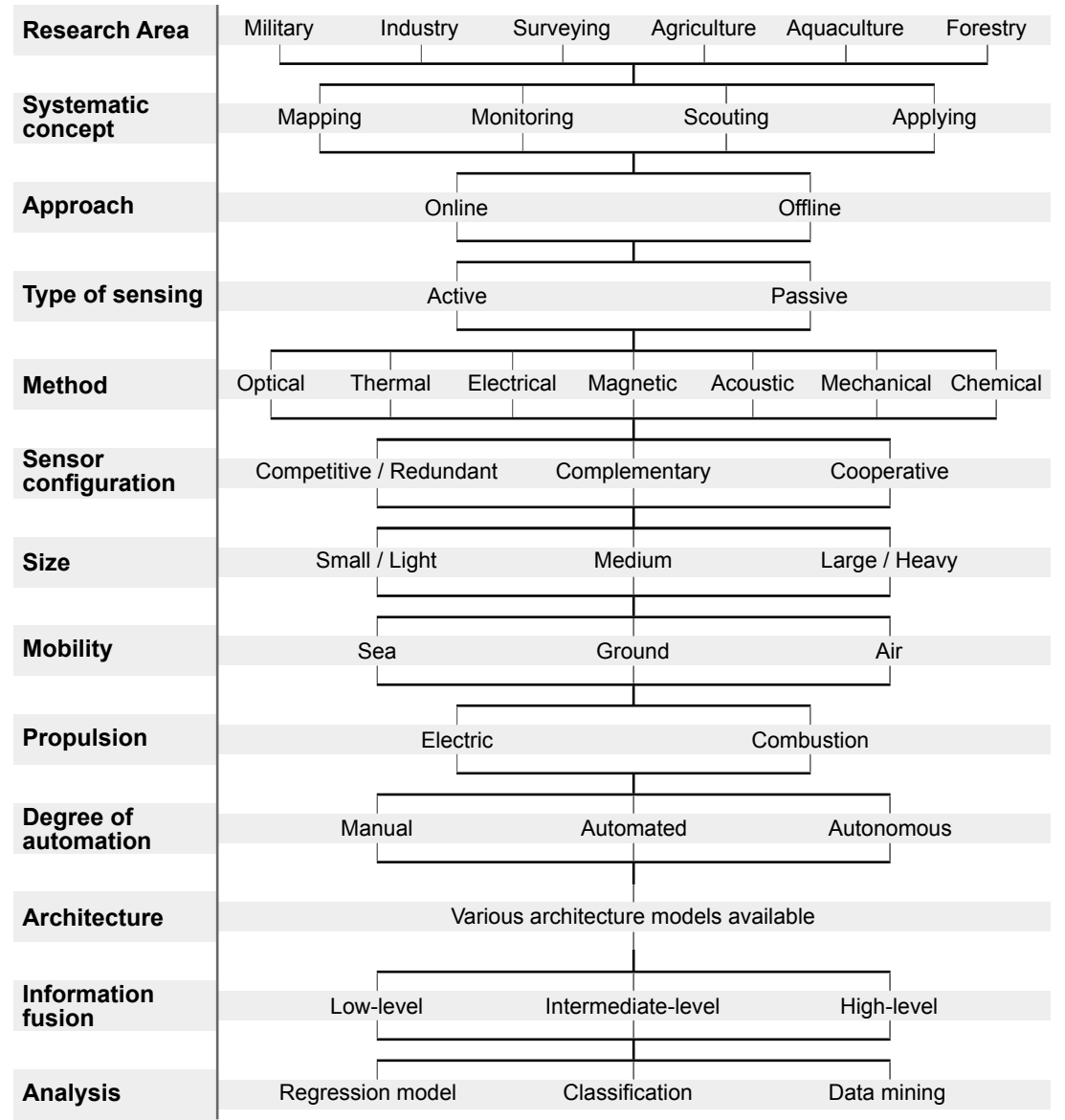

Figure 1. A general platform categorisation tree (according to Compton et al., 2013).

availability of new sensor and information system technologies, offline techniques can be replaced by online methods (Fender et al., 2006). So far, mainly online technology is implemented in practical agriculture. However, current and future concepts include the combination of online and offline approaches, so-called mapping-overlay approaches (Auernhammer, 2001).

\subsection{Type of sensing}

The technology differs between active and passive sensor methods. Passive sensors are dependent on ambient light conditions. They use principles of solar radiation to measure or image the energy remission of the sighted object. Active sensors provide their own illumination source and are able to obtain measurements regardless of time, day or season (Hoge et al., 1986). Nowadays, mainly active sensors with their own laser- or LED-light source are preferable. Increased measurement time and sensor operations, due to independence of natural sunlight, are the advantages of such systems.

\subsection{Methods of sensing}

In the area of agriculture, at the moment mainly spectrometers are implemented (Maidl et al., 2004). Also, electrical sensor systems, e.g. for soil electrical resistivity or electromagnetic induction, are used to explain soil heterogeneity in fields (Corwin and Lesch, 2003; Knappenberger and Köller, 2011). Other sensor principles, e.g. mechanical feelers, are used for machine guidance in row crops (Reid et al., 2000). A challenging research task is achieving high detection accuracy with chemical sensors. Marrazzo et al. (2005) tested intact apples and their extracted juice. The authors sought to detect similarities with an electronic nose in laboratory conditions. However, outdoor applications with the same system set-up and detection accuracy will be challenging to adapt. Zarco-Tejada et al. (2012) have been working for some years in the topic of detecting water stress with thermal sensors on an aerial platform. Registering the echoes reflected by the ground or plant surface, Andújar et al. (2011) implemented an ultrasonic sensor for weed discrimination. 


\subsection{Sensor configuration}

Durrant-Whyte (1988) specified three types of sensor configuration: (1) a competitive or redundant, (2) a complementary, and (3) a cooperative sensor configuration.

Competitive or redundant configurations stands for two or more sensors which supply information of the same parameter at the same location and the same degrees of freedom. It serves for increased accuracy and high reliability of the whole sensor system configuration.

Two or more sensors supplying different information about the same parameters at the same location and in different degrees of freedom are called complementary sensors. As there is no direct dependency of the sensors in a complementary configuration, it completes the information of the measurement situation.

The cooperative sensor configuration consists of independent sensors which rely on another for information. It offers emerging views on situations (Elmenreich, 2002).

\subsection{Size}

Depending on the efforts, incorporating multiple sensors to one system, the sensor configuration type impacts on the final costs as well as the required size and final weight of the platform. The size of a mobile sensor platform is directly correlated with the possible payload, thus on small mobile sensor platforms only light sensors can be implemented. The bigger the vehicle, the more requisites need to be fulfilled due to federal regulations or ambient claims. Also, due to technological development, platform sizes have become smaller and smaller, down to hummingbird size with only $19 \mathrm{~g}$ and a small video camera (AeroVironment Inc., 2013).

\subsection{Mobility}

Using a vehicle or a mobile platform for data acquisition offers the possibility of automation or autonomy of a system, and, compared to manual data sampling, more ground coverage is possible. Process routines can be adapted on the mobile system via an architecture model, for merging data, increased analysis speed and less operator fatigue or failures. Data transmission is linked to a server and enables live views of the acquired data. In case of measurement errors, the operator is able to react immediately, repeating the data acquisition or changing the adjustments due to an easier system overview. The decisions and necessities of a project affect the mobility of the operated platform, which will be explained in detail in the following.

\subsubsection{Sea vehicles}

Aquaculture is facing the situation of a continuously growing fish consumption. Fish farms benefit from research done in marine applications to reduce stress on the fish and for better observation of fish cages (Frost et al., 1996). While Frost et al. (1996) published results about a prototype of a Remotely Operated Vehicle (ROV), He et al. (2011) showed an example for a navigation method of an Autonomous Underwater Vehicle (AUV). Osterloh et al. (2012) advanced in that research by explaining AUV systems operating in swarms. At the web page for AUV (http://www.transit-port.net), Zimmer (2013) offers recent information about the whole range of submarine vehicle applications.

\subsubsection{Self-propelled ground vehicles}

Ground vehicles have the advantage of high-resolution sensing and less disturbance factors (Reyniers et al., 2004). Their benefit is the ability to carrying higher loads and more equipment than it would be possible by manual hand sampling. Combustion engines are coupled with the battery and therefore they are able to offer a mobile power supply for electric sensor devices. The mission planning is more flexible compared to sensing with full-scale aircrafts and it is less sensitive to ambient weather conditions. Their disadvantages are lower surface coverage and the influence on traction and trafficability due to different terrain types or obstacles (Hague et al., 2000). In the automotive sector projects with autonomous cars are quite advanced (e.g. "Google Car" Google Inc. \& Stanford University, CA, USA or "Leonie" Volkswagen \& Technical University of Braunschweig, Germany) (Moore and Lu, 2011; Saust et al., 2011). Within the Carolo-Cup event, German student groups are requested to develop the best possible guidance for an autonomous vehicle in different scenarios like obstacle avoidance (Maurer, 2013). On the web portal http://www.therobotreport.com, Tobe (2013) informs about educational institutions, research facilities and labs working in robotics and publishes continuously other related news in this area. More details about special ground carrier systems for agricultural usage will be given in Sect. 3.1.

\subsubsection{Remote and aerial platforms}

After the successful start of powerful ballistic missiles, satellites in the orbit have been used for a wide range of applications, like navigation, weather research, telecommunications or environmental monitoring (Richharia, 1999). For agricultural scope, the spectral properties of the vegetation are important (Tucker and Sellers, 1986). Images provided by satellites are a common source for analysing larger regions or fields in order to detect crop health, nutrient supply, weed patches or the general crop condition (Tucker and Sellers, 1986; Moran et al., 1997; Pinter et al., 2007; LópezGranados, 2011; Bernardes et al., 2012). However, the limits often lie in the low spatial resolution of these images or cloud covers in the images. For small-scale areas of interest, e.g. field trials in agriculture, higher data resolution needs to be gathered in order to have a better detection precision in the surveyed area. Firstly, the usage of manned full-scale 
Table 1. Categorisation and definitions of unmanned aircraft systems (based on Allen et al., 2011). MTOW = maximum take off weight.

\begin{tabular}{lllll}
\hline UAS Category & Acronym & Altitude $[\mathrm{m}]$ & Endurance $[\mathrm{h}]$ & MTOW $[\mathrm{kg}]$ \\
\hline Nano Aerial Vehicle & NAV & 100 & $<1$ & $<0.025$ \\
Micro Aerial Vehicle & MAV & 250 & 1 & $<5$ \\
Mini Aerial Vehicle & MAV & $150^{\mathrm{a}-300^{\mathrm{b}}}$ & $<2$ & $<30\left(150^{\mathrm{a}}\right)$ \\
Close Range & CR & 3000 & $2-4$ & 150 \\
Short Range & SR & 3000 & $3-6$ & 200 \\
Medium Range & MR & 5000 & $6-10$ & 1250 \\
Medium Range Endurance & MRE & 8000 & $10-18$ & 1250 \\
Low Altitude Deep Penetration & LADP & $50-9000$ & $0.5-1$ & 350 \\
Low Altitude Long Endurance & LALE & 3000 & $>24$ & $<30$ \\
Medium Altitude Long Endurance & MALE & 14000 & $24-48$ & 1500 \\
High Altitude Long Endurance & HALE & 20000 & $24-48$ & $\left(4500^{\mathrm{c}}\right) 12000$ \\
\hline
\end{tabular}

$\mathrm{a}$ in Japan, ${ }^{\mathrm{b}}$ depending on national legislation, ${ }^{\mathrm{c}}$ Predator B.

aircrafts arose, which could be planned with more flexibility and much faster than satellites. Furthermore, they offer to carry most equipment loads. The mission costs are, however, disadvantageous. Within the last few years, the idea of using Unmanned Aerial Vehicles (UAV), i.e. unmanned aircraft systems (UAS) became popular. Their advantages are flexible use and inexpensive implementation without pilots on board. As for ground vehicles, several UAV competitions for students are arranged, e.g. the International Aerial Robotics Competition (IARC), with two parallel venues in Grand Forks, ND, USA and in Beijing, China, the UAV Challenge - Outback Rescue held in Kingaroy, QLD, Australia or the UAV Student Competition in Ottawa, Ontario, Canada with different types of aerial vehicles and customised sensors.

According to TheUAV (2013), "UAVs can be a remote controlled aircraft (e.g. flown by a pilot at a ground control station) or can fly autonomously based on pre-programmed flight plans or more complex dynamic automation systems". Advanced UAV can be equipped with built-in control and guidance systems to perform speed and flight path stabilization, as well as waypoint following, but they are not autonomous at all (TheUAV, 2013). The Civil Aviation Authority (CAA) defines a UAS as "individual 'System Elements' consisting of the unmanned aircraft (UA) and any other System Elements necessary to enable flight, such as a Remote Pilot Station, Communication Link and Launch and Recovery Element", whereas UAV is a legacy term and obsolete (CAA, 2012). Therefore, in the following, the term UAS will be used for describing aerial platforms.

Especially in the military sector, UAS are also named drones. Balloons and kites are excluded from this term. An important objective for UAS will be to operate without human intervention across all flight sectors (CAA, 2012). Besides the two terms UAV and UAS, many others are in use, like the vertical take off and landing (VTOL) system for copters (Watts et al., 2012), as well as remotely operated aircraft (ROA), remotely piloted vehicle (RPV) or unmanned aircraft vehicle system (UAVS) (IDGA, 2013; FAA, 2013; ICAO, 2011). The International Civil Aviation Organization (ICAO), an agency of the United Nations, started to use the term remotely piloted aircraft system (RPAS) instead of UAS (Allen et al., 2011).

Right now, there are still a lot of different terms in use which might cause confusion. The ICAO from Canada, the CAA from the UK, the Institute for Defence \& Government Advancement (IDGA), the Federal Aviation Administration (FAA) from the USA, as well as many other institutions like Eurocontrol from Belgium, the European Aviation Safety Agency (EASA) from Germany or the European Organization for Civil Aviation Equipment (EUROCAE) from France are working in the topics of definitions, standards and safety, concerning unmanned aircrafts (UA). In their publications further information is given, e.g. in ICAO Circular 328, CAP 722 , or WG 73 .

Watts et al. (2012) described classification terms for aerial vehicles depending on their flight time endurance, size and flight altitude following existing military descriptions. The officially used terms are summarised in Table 1 based on Allen et al. (2011), which are all referring to unmanned aircraft systems.

National regulations are however different everywhere and the discussion about safety and privacy has arisen. Only for private use in Germany, § 16 LuftVO permits a maximum take off weight (MTOW) of $5 \mathrm{~kg}$ for starting and landing everywhere. All other usages, independent of their MTOW, require a special permission due to federal regulations (BMJ, 2012). In the United Kingdom, according to $\S \S 166,167$, 253 ANO2009, no registration for an aircraft below $20 \mathrm{~kg}$ is needed, but an operating permission and an appropriate pilot qualification is required (CAA, 2009). The FAA in the USA restricts the usage of UAS to a maximum of $122 \mathrm{~m}$ (400 feet) above ground level and sufficient distance to populated areas and full-scale aircrafts. For business purposes a Special Airworthiness Certificate-Experimental Category (SAC-EC) is required additionally (FAA, 2013). 
Table 2. Different types of UAS categorised into different propulsion and wing types.

\begin{tabular}{cc}
\hline \multicolumn{2}{c}{ Electric-Combustion/Jet-turbine } \\
\hline Fixed Wing & Rotary Wing \\
\hline $\begin{array}{cc}\text { Wing aircraft } \\
\text { Flying/Delta wing }\end{array}$ & $\begin{array}{c}\text { Helicopter } \\
\text { Multicopter }\end{array}$ \\
\hline
\end{tabular}

Within the last decade platform sizes have become smaller and smaller since starting with RS data acquisition. As an example for aerial platforms, the decrease was from (1) satellites, to (2) full-scale aircraft. Nowadays, (3) multicopter are used more frequently, and the actual smallest aerial vehicle is the size of a (4) hummingbird. Increasing in relevance to research projects is the micro aerial vehicle (MTOW $\leq 5 \mathrm{~kg}$ ) and mini aerial vehicle (MTOW $<30 \mathrm{~kg}$ ). In recent years, an important focus of research groups was on the implementation of helicopters and microcopters. A variety of terrains makes their usage highly flexible and adaptable to many different tasks. Specific groups working in the field of UAS for research are presented in Sect. 3.2. Beside wind and rotor air vehicles, flapping wing UAS, e.g. from the Dutch company Green X (Enschede, Netherlands) or the "SmartBird" from the German company Festo (Esslingen, Germany), are currently in developmental focus. Another milestone with flapping wing technology is a nano UAS, the "Nano Hummingbird", by the US company AeroVironment, Inc. (Monrovia, CA, USA). This UAS has a wingspan of $16 \mathrm{~cm}$, a TOW of only $19 \mathrm{~g}$, and is equipped with a small colour video camera (AeroVironment Inc., 2013).

\subsection{Propulsion}

Depending on the time duration for each campaign or the power requirement of the whole system, the propulsion type for the mobile sensor platform needs to be selected. The energy supply for a platform with the auxiliary equipment is a fundamental criterion. UAS propulsion can be further differentiated by several criteria (see Table 2). While on the ground, electric and piston-driven vehicles are common; in aerial applications, turbine propulsion has also been developed. Installations on ground platforms can have hybrid systems installed, i.e. where a combustion engine powers the gear drive, and an alternator charges the battery. As combustion engines cause higher levels of vibration, electric drives are implemented mainly on small aerial platforms. On larger aerial platforms $(>10 \mathrm{~kg})$, combustion engines are necessary to ensure higher flight time endurance and more range. The energy supply for a platform with the auxiliary equipment is a fundamental criterion.

\subsection{Degree of automation}

Manual applications require much supervision. Errors can happen with increasing numbers of working hours, causing lower repeatability accuracy. The more complex the process, the more possible sources for errors are given. Therefore, process automation was enforced in many areas to reduce human errors and improve quality and quantity. The more independent the degree of automation, the more complex the whole system is. "Automated" and "autonomous", are terms that have to be differentiated.

Automation in general means "the application of machines to tasks once performed by human beings or, increasingly, to tasks that would otherwise be impossible" (Encyclopaedia Britannica, 2013). Reasons for process automation are improved and uniform quality, increased performance, reduction of process costs and relief of human burden of heavy physical or monotonous work (Schuler, 1994). While automation rules can have many dependencies, interactions and linkings, a system failure would need to be resolved by a system specialist.

Autonomy covers the concepts of freedom from intervention, oversight or control of an operator or another system for decision making (e.g. Evans et al., 1992; Barber and Martin, 2001), and has a more comprehensive meaning of independence of control with learning, development and reacting processes (Smithers, 1997; Pfeifer and Scheier, 2001).

Automated and autonomous systems can substitute the most trivial working routines, are able to reduce labour costs and are not dependent on restrictions regarding the number of hours in a working day. If automated or autonomous technology are to be available on the market, easy-to-use controls are necessary. The operator needs to have a system that is easily adjustable and manageable whilst an architecture behind regulates the necessary system modifications. A remote service support, in combination with an online diagnostic tool (e.g. realised with telemetry systems), could be a solution to merge both needs. The main reason for the implementation of autonomous instead of manual or automatic systems is their ability to react. This is fundamental for control processes. Autonomous systems are capable to detect obstacles and to react immediately, i.e. they can move around and avoid a collision. Automated systems have serious problems if an obstacle appears (e.g. Crowley, 1985).

\subsection{Software architecture}

According to Orebäck and Christensen (2003), the most efficient strategy for designing autonomous systems or robots is the implementation of a software architecture. Moreover, Nebot et al. (2011) explained the importance of a controlling architecture in order to run a mobile sensor platform with a higher degree of automation. As the most important part of a robotic system, it has to allow coordination and cooperation between the different system elements. "The right 
Table 3. Architecture models for field robots, sorted by year of publication. Latest information 5 April 2013.

\begin{tabular}{llll}
\hline Architecture model & & Author & Year \\
\hline Blackboard control & - & Hayes-Roth & 1985 \\
Saphira & - & Konolige et al. & 1997 \\
TeamBots & Team robots & Balch & 2013 \\
BERRA & Behaviour-based Robot Research Architecture & Lindström et al. & 2000 \\
Umbra & "Shadow" (lat.) & Gottlieb et al. & 2001 \\
CARMEN & Carnegie Mellon Navigation & Montemerlo et al. & 2003 \\
MARIE & Mobile and Autonomous RoboticsIntegration Environment & Côté et al. & 2006 \\
ORCA & Organic Robotic Control Architecture & Makarenko et al. & 2006 \\
AGROAMARA & Agricultural Autonomous Multi-Agent Architecture Robot & García-Pérez et al. & 2008 \\
ROS & Robot Operating System & Quigley et al. & 2009 \\
MRDS & Microsoft Robotics Developer Studio & Cepeda et al. & 2010 \\
AGRITURE & AGRIcultural architecTURE & Nebot et al. & 2011 \\
FroboMind & Field Robot Architecture & Jensen et al. & 2012 \\
\hline
\end{tabular}

choice of the architecture can facilitate the specification, implementation and validation of the applications implemented for the system" (Nebot et al., 2011). Robot architecture has been developed with having in mind principles such as scalability, code reuse, abstraction hardware and data distribution (Nebot et al., 2011). "Having a universal system, modularity, openness, extendibility and simplicity are important assets" (Orebäck, 2004). Makarenko et al. (2006) proposed that a "successful framework for a robot should be (1) open source, (2) distributed under a license which allows use in commercial applications, (3) modular, and (4) distributed with a repository of tested and documented modules."

A comparison among different contemporary architectures for robots is shown and evaluated by Nebot et al. (2011). The authors discussed architectures for the field of cooperative robot systems (see Sect. 2.6 Sensor configuration). A summary list of architecture models of robots and platforms is given in Table 3. One of the first systems for the problemsolving process of artificial intelligence was the blackboard control architecture. It consists of three major components: (1) software specialist modules, (2) a blackboard like a dynamic library, and (3) a control shell. The control unit acts as a gatekeeper to determine which independent computational modules could communicate to the blackboard at what time (Hayes-Roth, 1985). Orebäck and Christensen (2003) studied more recent results by describing three architectures: (1) Saphira, (2) TeamBots, and (3) BERRA. Saphira (Konolige et al., 1997) is a robot control system with integrated routines for sonar sensor interpretation, map-building and navigation. The system TeamBots by Balch (2013) was used for single- and multi-agent mobile robotics while BERRA (Behaviour based Robot Research Architecture) (Lindström et al., 2000), the most complex system of these three, was designed for goals of scalability and flexibility (Orebäck and Christensen, 2003). The aim of their study was to give an overview of existing architectures. Finally, they proposed a generic design for a new robot architecture.
The framework Umbra enables the generation of models and simulations for intelligent system development, analysis, experimentation and control. Umbra supports the analysis of complex robotic systems and bridges between low-level engineering and constructive-level scenario simulation environments (Gottlieb et al., 2001). It is a commercial product of Sandia National Laboratories (Albuquerque, NM, USA). Another product they offer is also used for robots; the so-called SMART, the Sandia Modular Architecture for Robotics and Teleoperation. CARMEN is an open-source robot control toolkit and was created for ease of use, robustness and extensibility. It was designed as a modular software architecture with modules containing localisation, collision detection, navigation, and hardware management and communication (Montemerlo et al., 2003). The open-source framework ORCA is a component-based robotic systems for developing purposes, released under LGPL and GPL (GNU (Lesser) General Public License) licenses. It provides the means for defining and developing the building blocks, which can be pieced together to form arbitrarily complex robotic systems. For development and integration of new and already existing robotic software, the framework MARIE (Mobile and Autonomous Robotics Integration Environment) was designed (Makarenko et al., 2006). García-Pérez et al. (2008) designed an agent of behaviour architecture named AGROAMARA, for autonomous navigation of a mobile robot. This multi-agent architecture was implemented on an articulated tractor and offers a methodological framework for farming operations, perception and control algorithms. The Robot Operating System (ROS) was developed in 2007 by Stanford University, USA. "ROS encourages well-defined data flows through ROS-topics and has become popular in recent robot projects due to its open-source BSD (Berkeley Software Distribution) license and good online documentation" (Quigley et al., 2009). Cepeda et al. (2010) presented the Microsoft Robotics Developer Studio where they tested speech recognition, vision and sensor-based navigation. The MRDS 
environment was programmed for robot control and simulation and allows for the achievement of complex behaviours for a wide variety of robot hardware. AGRITURE was designed for implementation of a control system on a team of mobile robots in agricultural environments. It can interact with real and simulated devices, which is useful for optimizing the whole system (Nebot et al., 2011). FroboMind, based on ROS, is a conceptual architecture for a robot control system. It is open-source and designed for field robotics research. The concept was recently presented at the CIGRAgEng 2012 conference by Jensen et al. (2012).

\subsection{Information fusion}

The terminology used to describe fusion systems is used in a wide and diverse variety of ways in the literature. In technical publications, the terms "sensor fusion", "data fusion", "information fusion", "multi-sensor data fusion" or "multi-sensor integration" refer to different techniques, technologies, systems or applications with gathered data from multiple information sources (Rothman and Denton, 1991). "Dasarathy (2001) decided to use the term 'information fusion' as the overall term for fusion of any kind of data" (Elmenreich, 2002). An exact definition of information fusion is given by the International Society of Information Fusion (ISIF): "Synergistic integration of information from different sources about the behaviour of a particular system, to support decisions and actions relating to the system." Elmenreich (2002) introduces sensor fusion as the "Combining of sensory data, or data derived from sensory data, from disparate sources such that the resulting information is in some sense better than would be possible when these sources were used individually."

Basically all creatures do sensory and information fusion. Each in their own way, they combine the impressions of different senses with learned knowledge, experience and messages from living environment (Elmenreich, 2002). Regardless of their terminology, sensor fusion techniques all benefit from (1) robust performance, (2) extended spatial and temporal coverage, (3) increased confidence, (4) reduced ambiguity and uncertainty, (5) improved resolution, (6) improved system reliability, (7) robustness against interference, and (8) increased dimensionality (Bossé et al., 1996; Grossmann, 1998).

Based on Dasarathy (1997), fusion approaches can be categorised by a three-level model: (1) low-level fusion or raw data fusion, (2) intermediate-level fusion or feature-level fusion, and (3) high-level fusion or decision fusion. "Low-level fusion or raw data fusion combines several sources of raw data to produce new data that is expected to be more informative than the inputs" (Elmenreich, 2002). Intermediate-level fusion or feature level fusion fuses features like lines, edges, textures or positions from various data sources into a new feature map for increased information content (Elmenreich, 2002). "High-level fusion or decision fusion combines deci- sions from several experts. Methods of decision fusion include voting, fuzzy-logic, and statistical methods" (Elmenreich, 2002).

Fusion algorithms can be classified into four methods of (1) estimation, (2) classification, (3) inference, and (4) artificial intelligence. Configured in the modules of robot architecture, the fusion of information is a necessary step for data analysis and decision making. For autonomous vehicle navigation, data fusion is used, e.g. for visual target tracking (Luo et al., 2002; Jia et al., 2008).

\subsection{Data analysis}

The analysis of data is an essential part for coming to decisions and making applications. The analysis process consists of several parts. First, the generated data need to be controlled. For manual postprocessing a convenient data editor is necessary. The next step involves cleaning the data from irregularities or wrong information. Afterwards, the corrected data must be transformed to special file formats in order to analyse it with software programs for modelling. Several regression models are developed to analyse data. Classification algorithms are used widely for image analysis and fusion approaches. In addition to algorithm methods for classification tasks, data mining, (knowledge discovery) can be applied, but is still a rather unexplored process.

There are basically two uses of sensors on platforms; navigation sensors and mission sensors. An important principle, implemented to autonomous vehicles or robots, is the simultaneous localisation and mapping (SLAM), fusing navigation and mission sensor data. Different sensor types are used in such a system to acquire data from the environment. With this data, the analysis algorithms are defining the exact location of the vehicle and keeping its track (e.g. Durrant-Whyte and Bailey, 2006; Blanco et al., 2009).

\section{Sensor platforms in agriculture}

With the availability of satellite data for civil use, the analysis of spectral reflectance characteristics of plant canopies started in the late 1970s (Tucker, 1980; Tucker and Sellers, 1986). Since remote sensing (RS) research is an investigation topic with many scientists involved, the developed methods for detecting and classifying objects are advanced and used in many applications, e.g. in archaeology, geoinformatics, geophysics, land surveying, mining or agriculture. Lamb (2000) named three essentials for an RS system: (1) provide cost-effective data, (2) be capable of acquiring and providing information in a timely manner, and (3) have user-defined spectral characteristics to allow for adjusting of specific crop indicators (Lebourgeois et al., 2008).

All efforts done in agricultural research have to serve this goal: growing more and better output with less input and with less environmental impact. Sensor platforms can help to reach this goal by monitoring crop status and applying the 
Table 4. Robotic ground vehicles in research as possible platforms for agricultural scopes. The described robots are mainly from European research projects and private companies. Robot names are linked to more information. Latest information 7 May 2013.

\begin{tabular}{|c|c|c|}
\hline Robot name & Task(s) & Institution \\
\hline AROCO & $\begin{array}{l}\text { Obstacle detection, } \\
\text { Digital Elevation Map }\end{array}$ & $\begin{array}{l}\text { National Research Institute of Science and Technology for Environment and } \\
\text { Agriculture (CEMAGREF) \& LASMEA, Aubiere, France. }\end{array}$ \\
\hline $\begin{array}{l}\text { Large scale } \\
\text { unmanned tractor }\end{array}$ & Modular system & $\begin{array}{l}\text { Department of Automation and Systems Technology, Aalto University, } \\
\text { Espoo, Finland. }\end{array}$ \\
\hline Nuntius & Modular system & Dorhout, D., Dorhout R\&D LLC, Iowa, USA. \\
\hline Neobotix & Modular system & Neobotix GmbH, Heilbronn, Germany. \\
\hline Grizzly, Husky & Modular systems & Clearpath Robotics Inc., Kitchener, ON, Canada. \\
\hline Prospero & Modular system & Dorhout, D., Dorhout R\&D LLC, Iowa, USA. \\
\hline Robosoft & Modular system & Robosoft SA, Bidart, France. \\
\hline Volksbot & Modular system & Fraunhofer IAIS, Sankt Augustin, Germany. \\
\hline
\end{tabular}

right amount of nutrients or pest controls, but actually, more work needs to be invested. Mostly, single sensor approaches on vehicles are used in combination with true ground sample data as reliable reference.

\subsection{Ground vehicles}

In the early 1970s, researchers had already taken advantage of ground vehicles for RS data collection (Al-Abbas et al., 1972). Since this time, an increasing number of sensor platforms and robots have been developed. The web portal for Agricultural Robotics (http://www.unibots.com) gives a general informative overview. Several robots used in research projects for agricultural purposes are described. The web page lists finished, as well as ongoing, agricultural robot projects and their managed tasks (Blackmore, 2013). Growing numbers of new projects show their strong relevance in today's agriculture due to high prices of resources and increased demand of organically grown food, as well as fast advances in technology. Sensor platforms and robots in agricultural usage are still part of research topics at universities, some of them in collaboration with industry partners (Blackmore, 2013; Tobe, 2013). Most recent robotic vehicles, as listed in Table 4, can provide a possible basis for future RS platforms in agriculture. Table 5 gives an overview of the robotic ground vehicles equipped with RS equipment mainly from European research projects.

In the following, applications implemented on ground platforms will be described with the approaches being used and their focus on crop and soil characteristics.

\subsubsection{Platforms for gathering soil data}

Site-specific information about soil, which provides information about yield limiting factors, can be used to derive management zones within a heterogeneous field and thus provide the possibility to apply input factors based on the existing demand (Fraisse et al., 2001; Mzuku et al., 2005). Sensors that operate close to the soil surface are not affected by weather and field surface conditions, but only a few sensors are commercially available for on-the-go measurement of soil properties (Adamchuk et al., 2004). Taylor et al. (2006) presented experiences and results for soil-property sensing on a multi-sensor platform. Mounted on a John Deere tractor, Sibley et al. (2008) implemented a soil nitrate mapping system, which showed the same accuracy in the field as in the laboratory. Dabas et al. (2000) used a sensor to measure the electrical resistivity in soil. As a further step, a sensor system for soil sensing, integrating electrical conductivity and $\mathrm{pH}$ mapping on a tractor-implement combination, has been investigated by Jonjak (2011), where fields were mapped with online sensing technology, as well as systematic grid sampling. Adamchuk et al. (2010) explained fusion approaches for soil and crop data and their importance. The running European project OPTIFERT is aiming at the realisation of a sensor platform for georeferenced measuring of different soil ions to allow precision fertilisation (Doyle et al., 2013).

\subsubsection{Platforms for plant characteristics}

Plant characteristics such as biomass, leaf area index or nutrient status provide information about the current status of the plants, which hints at growing conditions within the field. Faster detection and analysis methods for plant characteristics can support the reduction of lots of manual work for data acquisition. In plant breeding this is still a necessary step. Plant phenotyping like in the German project BreedVision can help to attain precise results in plant-breeding processes. Morphological and spectral information in crops with low density, e.g. corn, are measured and automatically fused together. This is done with a light-curtain, spectrometer, RGB (Red Green Blue) camera, 3-D-Time-of-flight cameras and a distance sensor (Busemeyer et al., 2010). The fluorescence sensor, Multiplex ${ }^{\circledR}$ (Force-A, Orsay, France), used at the University of Hohenheim, Stuttgart, Germany showed good correlations to nitrogen status and yield in winter wheat (Martinon et al., 2011). Stabilizing algorithms for video cameras can be integrated for inter-row navigation and 
Table 5. Ground platforms equipped with remote sensing equipment for agricultural purposes. Robot names are linked to more information. Latest information 7 May 2013.

\begin{tabular}{|c|c|c|}
\hline Robot name & Task(s) & Institution \\
\hline Armadillo Scout & $\begin{array}{l}\text { Obstacle detection, } \\
\text { scouting, 3-D-mapping, } \\
\text { weeding }\end{array}$ & $\begin{array}{l}\text { Griepentrog, H. W. et al., Department for Instrumentation and Test Engineering, } \\
\text { University of Hohenheim, Stuttgart, Germany, University of Southern Denmark, } \\
\text { Odense, Denmark and KU-LIFE, University of Copenhagen, Denmark. }\end{array}$ \\
\hline ASuBot & $\begin{array}{l}\text { Obstacle detection, } \\
\text { weeding }\end{array}$ & $\begin{array}{l}\text { Jensen, K. et al., Institute of Chem-, Bio- and Environmental Technology, Univer- } \\
\text { sity of Southern Denmark, Odense, Denmark and Aarhus University, Denmark. }\end{array}$ \\
\hline BoniRob & Plant phenotyping & $\begin{array}{l}\text { Ruckelshausen, A. et al., University of Applied Sciences, Osnabrück, Germany and } \\
\text { Amazonen-Werke H. Dreyer GmbH \& Co. KG, Hasbergen, Germany. }\end{array}$ \\
\hline BreedVision & Plant phenotyping & $\begin{array}{l}\text { Ruckelshausen, A. et al., University of Applied Sciences, Osnabrück, Germany, } \\
\text { Amazonen-Werke H. Dreyer GmbH \& Co. KG, Hasbergen, Germany and State } \\
\text { Plant Breeding Institute, University of Hohenheim, Stuttgart, Germany. }\end{array}$ \\
\hline DEDALO & $\begin{array}{l}\text { Obstacle detection, de- } \\
\text { tection and classifica- } \\
\text { tion of objects }\end{array}$ & $\begin{array}{l}\text { García-Alegre, M. C. et al., Centre for Automation and Robotics, Spanish National } \\
\text { Research Council \& Systems Engineering and Automation Department, Carlos III } \\
\text { University of Madrid, Spain. }\end{array}$ \\
\hline Hako & $\begin{array}{l}\text { Obstacle detection, } \\
\text { mowing, precision } \\
\text { seeding, hoeing, } \\
\text { spraying }\end{array}$ & $\begin{array}{l}\text { Griepentrog, H. W. et al., Department for Instrumentation and Test Engineering, } \\
\text { University of Hohenheim, Stuttgart, Germany and KU-LIFE, University of Copen- } \\
\text { hagen, Denmark. }\end{array}$ \\
\hline HortiBot & $\begin{array}{l}\text { Row detection and } \\
\text { spraying }\end{array}$ & $\begin{array}{l}\text { Melander, B., Aarhus University, Denmark and Research Centre Flakkebjerg, } \\
\text { Slagelse, Denmark. }\end{array}$ \\
\hline Robotic arm & $\begin{array}{l}\text { Plant care \& nutrition, } \\
\text { fruit harvesting }\end{array}$ & $\begin{array}{l}\text { Johnson, L. and Dyar, S., Massachusetts Institute of Technology (MIT), Cam- } \\
\text { bridge, MA, USA. }\end{array}$ \\
\hline Sensicle & $\begin{array}{l}\text { Weed detection, crop } \\
\text { nitrogen status }\end{array}$ & Claupein, W., Gerhards, R., et al., University of Hohenheim, Stuttgart, Germany. \\
\hline Volksbot RT-3 mod & $\begin{array}{l}\text { Plant detection } \\
\& \text { mapping }\end{array}$ & Weiss, U. and Biber, P., Robert Bosch GmbH, Schwieberdingen, Germany. \\
\hline Weedcer & $\begin{array}{l}\text { Image analysis, } \\
\text { spraying }\end{array}$ & $\begin{array}{l}\text { Berge, T. W. et al., Norwegian Institute for Agricultural and Environmental Re- } \\
\text { search (Bioforsk), Ås, Norway, Adigo Ltd., Oppegård, Norway and SINTEF Infor- } \\
\text { mation and Communication Technology, Oslo, Norway. }\end{array}$ \\
\hline Zero2Nine & $\begin{array}{l}\text { Obstacle \& } \\
\text { row detection }\end{array}$ & $\begin{array}{l}\text { Linz, A., Ruckelshausen, A., et al., University of Applied Sciences, Osnabrück, } \\
\text { Germany. }\end{array}$ \\
\hline
\end{tabular}

field-mapping even if the terrain causes lots of vehicle vibrations (Sainz-Costa et al., 2011). Recognizing contextual information of crop rows by the use of machine vision on a platform was first tested in the early 1990s. The methods of steering a weeding tool within a few centimetres beside a plant were taken, enhanced and commercialised by Tillett and Hague (1999) and the Danish Institute of Agricultural Sciences (Søgaard and Olsen, 2003; Pedersen et al., 2006). With new software advances and algorithms for analysis, imaging devices are in use by many research groups. Other topics dealt with plant stress caused by diseases like powdery mildew (Bravo et al., 2004; Gröll et al., 2007) or take-all disease (Graeff et al., 2006). Shiratsuchi et al. (2009) used crop canopy reflectance and temperature sensing for nitrogen or water stress detection in combination with an ultrasonic sensor for crop height assessment.

\subsubsection{Platforms for plant protection}

Mobile sensor platforms were also implemented for plant protection. Slaughter et al. (2008) reviewed weed control systems on autonomous robots. The robots' biggest challenge remains detecting and identifying weeds under various agricultural conditions seen all over the world. Steiner et al. (2008) discussed innovative approaches in the area of remote and near range sensors used in site-specific plant protection. López-Granados (2011) recently reviewed the advances, limitations and opportunities of real-time and mapping approaches for discriminating weeds at early or late phenological stages for site-specific weed management in cropping systems. Several other projects are working on weed control approaches (Lee et al., 1999; Ruckelshausen et al., 2006; Weis, 2010), as weeds can be significantly reduced by using decision rules with modern sensor and application technologies (Gutjahr and Gerhards, 2010). Andújar et al. (2011) described an ultrasonic sensor approach for automatic discrimination between broad-leaved weeds and grasses based on 
plant height with a high detection success. Due to recognized resistances of crops to chemicals and decreasing numbers of available active chemical substances, advances in mechanical weeding are more relevant than ever. The challenge is to remove weeds in all three locations: (1) inter-row, (2) intra-row, and (3) close-to-crop (Nørremark et al., 2011). For inter-row weeding, commercial solutions are already available, and intra-row applications are in development (Jørgensen et al., 2007; Kam et al., 2009; Fischer, 2012). Recently, Slaughter et al. (2012) presented an intra-row weed control system for mechanical plant protection with a hoe in order to remove weeds growing between tomato plants. In order not to damage the plant during the application, they documented each position of the sown tomato seeds with RTK accuracy. The ongoing RHEA (Robot Fleets for Highly Effective Agriculture and Forestry Management) project (http://www.rheaproject.eu), was launched in September 2010, and its' goal is the reduction of chemicals in agriculture through the use of automated ground and aerial systems. An autonomous tractor could be used for mechanical and thermal weed control (RHEA, 2013).

In "Autonomous Systems for Plant Protection", Griepentrog et al. (2010) described vehicles for monitoring, scouting and applying tasks, still being scaled to a research-based level of use. The main application for this group of robots will be firstly scouting and monitoring, including more advanced concepts in agricultural automation, such as the application of herbicides or autonomous mechanical weeding. The authors came to the conclusion that in countries with high product quality standards, high safety and environmental concerns, as well as high labour costs, robots allow economic cost reductions. Increased operational efficiencies and avoidance of negative environmental impacts are also positive effects of their use.

\subsection{Unmanned Aerial Systems}

UAS are already used in many research groups (Eisenbeiss et al., 2011; Herbst, 2012; Zhang and Kovacs, 2012). Due to their low price, low weight and flexible use, they are a popular tool for economical RS data acquisition. These aerial systems are promising tools to gather data in a shorter time than by a ground-based field vehicle, and in a cheaper way than it would be possible using a satellite or full-scale aircraft. UAS equipped with digital cameras are used for obtaining data, e.g. to create Digital Elevation Models (DEM) or Digital Terrain Models (DTM) for land surveying purposes (Turner et al., 2012) or for monitoring soil erosion (d'Oleire Oltmanns et al., 2012). Due to weight issues for enhanced flight time, only small GPS receivers with low accuracy are used on small UAS (Bláha et al., 2012).

Several projects with UAS used in agriculture are listed in Table 6 with payload capacity (PL), maximum take off weight (MTOW) and sensor configuration on the vehicles. Many other universities are working with UAS in non- military fields, e.g. the University of Stuttgart, Germany (Kittmann et al., 2011), the ETH Zurich, Switzerland (Bäni, 2011), the Bochum University of Applied Sciences, Germany (Bäumker et al., 2012) or the Delft University of Technology, Netherlands (de Croon et al., 2012). The Autonomous Vehicle Group at Aalborg University, Aalborg, Denmark is focusing on autonomous helicopters. Their research is broad and reaches from slung load flight, flights in turbulent wind conditions, wind power meteorology but also to applications with multispectral cameras, localization in swarms or monitoring the Arctic environment (la CourHarbo, 2013).

Due to the fact that an increasing number of scientists are working with these kind of planes and copters, Table 7 lists main commercial vendors for MAVs in rotary and fixed-wing configurations as an information source for aerial data acquisition projects in future.

\subsubsection{UAS for plant characteristics}

Within the last 5 yr UAS were also implemented into the agricultural research to gather information about plant characteristics and quality. Franke et al. (2008), in collaboration with the German Aerospace Center (DLR, Cologne, Germany), detected powdery mildew in wheat with the airborne Hyperspectral Mapper (Spectra Vista Corp., NY, USA). Two hand-held spectrometers and an airborne hyperspectral camera were compared by Øvergaard et al. (2010) for predicting grain yield and quality in spring wheat. At the University of Hohenheim, Germany, aerial reflectance measurements are conducted with a digital RGB camera (Optio10, Pentax Ricoh Imaging Co. Ltd., Tokyo, Japan) and a spectrometer device (tec5 AG, Oberursel, Germany) (Link-Dolezal et al., 2010, 2012). Lelong et al. (2008) showed that the quality of spectral ranges reached by standard digital cameras is suitable for RS, and that data preprocessing is quite effective. Hunt Jr. et al. (2010) used a filter for red light on several digital cameras without a near infrared (NIR) blocking filter on a UAS. With these calibrated cameras, they conducted good correlations at $210 \mathrm{~m}$ between green normalized difference vegetation index (gNDVI) and leaf area index (LAI). Also, Rabatel et al. (2012) used a single standard digital RGB camera for aerial field imaging at low altitude. They replaced the internal NIR blocking filter by a low-pass filter set. This method is a promising approach for a low-cost aerial sensor system. In southern countries, a very hot and dry summer is driving the need for irrigation. Better distribution of water can be achieved by early detection of plant stress due to water insufficiency. Therefore, Zarco-Tejada et al. (2012) used a UAS from QuantaLab IAS - CSIC, Córdoba, Spain, equipped with a thermal and a hyperspectral camera. Their results showed that crown temperature and chlorophyll fluorescence were the best indicators for water stress detection. However, fluorescence techniques within agricultural sensing platforms are still today barely in use due to the need 
Table 6. Recent UAS (research) projects with agricultural background (Eisenbeiss et al., 2011). PL = Payload, MTOW = maximum take off weight, RGB = Red Green Blue, NIR = Near infrared. Project names are linked to more information. Latest information 7 May 2013.

\begin{tabular}{|c|c|c|c|c|}
\hline Project name & Institution & $\begin{array}{l}\text { PL } \\
{[\mathrm{kg}]}\end{array}$ & $\begin{array}{l}\text { MTOW } \\
{[\mathrm{kg}]}\end{array}$ & Sensors \\
\hline & Fixed wing & & & \\
\hline AggieAir & Utah State University, Logan, UT, USA & 1.36 & 3.62 & RGB + NIR camera \\
\hline Altimum $3 \mathrm{e}$ & L'Avion Jaune, Montferrier-sur-Lèz, France & 4 & 15 & RGB + multi-spectral camera \\
\hline ARTINO & Fraunhofer FHR, Wachtberg, Germany & 5.4 & 25 & Radar \\
\hline Carolo 200 & Technical University of Braunschweig, Germany & 1.0 & $4-6$ & $\begin{array}{l}\text { RGB + Video camera, Meteoro- } \\
\text { logical measurement unit }\end{array}$ \\
\hline Carolo P330 & Technical University of Braunschweig, Germany & 2.5 & $15-25$ & Multi-spectral + thermal camera \\
\hline SENGIS & University of Hohenheim, Stuttgart, Germany & 1.8 & 4.2 & Spectrometer, RGB camera \\
\hline Stuttgarter Adler & University of Stuttgart, Stuttgart, Germany & 5.0 & 25 & $\begin{array}{l}\text { Spectrometer, RGB + thermal } \\
\text { camera }\end{array}$ \\
\hline
\end{tabular}

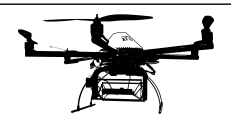

Rotary Wing/Multicopter

\begin{tabular}{lllll}
\hline Agricopter & Humboldt University of Berlin, Berlin, Germany & - & - & RGB + NIR camera \\
UAV-RS & University of Illinois, Urbana-Champaign, USA & 11.5 & 14.0 & Multi-spectral camera \\
ifgicopter & University of Münster, Münster, Germany & 0.3 & 1.1 & Temperature, Relative humidity \\
QuantaLab & QuantaLab IAS - CSIC, Córdoba, Spain & - & - & NIR camera \\
SENGIS & University of Hohenheim, Stuttgart, Germany & 2.0 & 4.3 & Spectrometer, RGB camera \\
Smart Skies & Australian Research Centre for Aerospace & - & 12.3 & Laser, stereo camera \\
& Automation, Brisbane, Australia & & & Multi-spectral camera \\
VIPtero & National Research Council, Firenze, Italy & 1.0 & - & \\
\hline
\end{tabular}

of having direct or very close contact to the analysed object (Tremblay et al., 2011).

\subsubsection{UAS for environment and weeds}

The $\mu$ Drones project (Micro Drone Autonomous Navigation for Environment Sensing) project, completed in 2010, dealt with topics monitoring public and private sites, as well as the support of security teams in their work ( $\mu$ Drones, 2013). From the results concerning hardware and software configurations, adaptions to related fields like agriculture can be done easily. In 2010, Acevo-Herrera et al. (2010) published their results of airborne soil moisture mapping in cereal and vineyard fields with a small UAS. Using a light radiometer at $1.4 \mathrm{GHz}$, they achieved low absolute errors in homogeneous fields. Merz and Chapman (2011) used an autonomous helicopter for RS missions in unknown environments. The copter has been successfully deployed for autonomous image capturing for plant phenomics studies, and later, in a use case, Geipel et al. (2011) presented how to detect weed spots with a multicopter and offer it as a service for PF. As the occurrence of weeds has a major influence on crop yield, the classification of weeds and the detection of weed patches play an important role in agricultural research. Segmentation and classification rules over arid rangelands (Laliberte and Rango, 2008) and over crops (Peña-Barragán et al., 2012) showed satisfactory and accurate results for species, group of species and for crop rows. Inside the RHEA project, PeñaBarragán et al. (2012) are using a multispectral camera on a multicopter for weed detection. The classification of image mosaics can be used for mapping and monitoring purposes. The demonstrated approaches are efficient and scalable for classification of similar vegetation.

Mapping of Mediterranean riparian forests was the focus of Dunford et al. (2009). They achieved overall classification accuracies of $63 \%$ and $71 \%$ for four species-level classes.

\subsection{Autonomous platforms and swarm technology}

In the near future, sensor platforms used in agriculture can become a smaller and smarter form of a robot. In reporting the experience of Nielsen et al. (2006), two criteria have to be taken into account regarding the development of an agricultural robot: (1) tool changing with dynamic adoption to new applications with necessary implements, and (2) human intervention so that the operator is able to change and influence the system due to current and future needs. Based on the thesis of Appel and Nielsen (2005), Nielsen et al. (2006) 
Table 7. Commercial suppliers of rotary and fixed wing hardware. Product name is linked to more information. Latest information 7 May 2013.

\begin{tabular}{|c|c|c|}
\hline Company & Product name & Country \\
\hline \multicolumn{3}{|l|}{ Micro rotary wing/multicopter $(\leq 5 \mathrm{~kg})$} \\
\hline Aeroquad Carancho Engineering LLC & Aeroquad & San Pedro, CA, USA \\
\hline AirRobot GmbH \& Co. KG & AR $100-B / 120 / 150 / 200$ & Arnsberg, Germany \\
\hline Ascending Technologies GmbH & Falcon 8 & Krailling, Germany \\
\hline Draganfly Innovations Inc. & Draganflyer & Saskatoon, SK, Canada \\
\hline EMT Ingenieurgesellschaft & FANCOPTER & Penzberg, Germany \\
\hline Fly-n-Sense & Scancopter X4/X6 & Mérignac Cedex, France \\
\hline geo-konzept $\mathrm{GmbH}$ & $\mathrm{X} 2000, \mathrm{X} 8000$ & Adelschlag, Germany \\
\hline Gyrofly Innovations & Gyro 200/500 & São José dos Campos, SP, Brazil \\
\hline microdrones $\mathrm{GmbH}$ & microdrone & Siegen, Germany \\
\hline Mikrokopter HiSystems GmbH & MikroKopter & Moormerland, Germany \\
\hline Multirotor & MR-X8 & Berlin, Germany \\
\hline Novadem & U130, NX110m & Meyreuil, France \\
\hline PC Quadrat GmbH & X3D-BL UFO & Nuremberg, Germany \\
\hline service-drone.de $\mathrm{GmbH}$ & G3 & Berlin, Germany \\
\hline Survex Copter & Copter 1b/City/4 & Pierrelatte, France \\
\hline \multicolumn{3}{|l|}{ Micro fixed wing $(\leq 5 \mathrm{~kg})$} \\
\hline AGX Tecnologia Ltda & Tiriba & São Carlos, SP, Brazil \\
\hline CALMAR Mapping Services & CALMAR Crop Condor & Remington, IN, USA \\
\hline CropCam Inc. & CropCam & Stony Mountain, MB, Canada \\
\hline Fly-n-Sense & Seeker 1300 & Mérignac Cedex, France \\
\hline Gatewing NV & $\mathrm{X} 100$ & Gent, Belgium \\
\hline Lehmann Aviation & LFPV, LM450, LP960, LV580 & La Chapelle Vendômoise, France \\
\hline SmartPlanes AB & Personal Aerial Mapping System & Skellefteå, Sweden \\
\hline senseFly SA & swinglet CAM, eBee & Ecublens, Switzerland \\
\hline Thamm Geo-Technic & Aurora, SUSI 62 & Linz am Rhein, Germany \\
\hline \multicolumn{3}{|l|}{ Mini Aerial Vehicle $(<30 \mathrm{~kg})$} \\
\hline Aeroscout $\mathrm{GmbH}$ & Scout B1-100 & Adliswil, Switzerland \\
\hline AGX Tecnologia Ltda & AG Plane, Arara T1/M1 & São Carlos, SP, Brazil \\
\hline Delft Dynamics B.V. & RH2 Stern & JD Delft, Netherlands \\
\hline SARL Infotron & IT180-5 TH/EL & Massy, France \\
\hline \multicolumn{3}{|c|}{ Mini Aerial Vehicle/Close Range $(<150 \mathrm{~kg})$} \\
\hline Swiss UAV AG & Neo, Koax, TU-150 Hybrid & Niederdorf, Switzerland \\
\hline
\end{tabular}

described further principals of multi-agent systems and the collaboration between robots. They outlined the ExplorerTransporter paradigm where the explorer consists of robot(s) for data acquisition in field and creating precise maps, and the transporter is the applicant of fertilizer or chemicals based on the information of the exploring unit(s).

Due to the smaller size and lower weight of future platforms, they will be less intrusive to soil. They will not be as weather dependent as today's big machinery, and will collect timely and accurate field information. The robots will be able to scout and treat each single plant individually (Blackmore et al., 2005). Blackmore and Griepentrog (2002) gave an outlook on autonomous platforms that may be available in the future. These autonomous platforms would be used for culti- vation and seeding, weeding, scouting, application of fertilisers and chemicals, irrigation and harvesting and would have the ability to work in teams as multi-units (McBratney et al., 2005).

A further logical step from automation and autonomy of mobile platforms is "swarm technology" or "swarm intelligence". Karaboga and Akay (2009) surveyed algorithms based on bee swarm intelligence. By adapting these approaches, several questions and challenges in research could be solved. To classify a swarm as having intelligent behaviour, Millonas (1992) defined the following five principles: 
1. Ability to do simple space and time computations (the proximity principle);

2. Ability to respond to quality factors in the environment such as the quality of foodstuffs or safety of location (the quality principle);

3. No single allocation of all resources along excessively narrow channels and it should distribute resources into many nodes (the principle of diverse response);

4. No change of its mode of behaviour upon every fluctuation of the environment (the principle of stability);

5. Ability to change behaviour mode when the investment in energy is worth the computational price (the principle of adaptability).

Robot swarms are in development with an increasing interest from a number of researchers working on the topic. Aside from the Technical University of Braunschweig, Germany, the Fraunhofer Institute, Karlsruhe, Germany, the ETH Zurich, Switzerland, as well the University of Pennsylvania, Philadelphia, PA, USA, and the Center for Collaborative Control of Unmanned Vehicles at the University of California, Berkeley, CA, USA are all working in the field of UAS swarm intelligence (Bürkle et al., 2011; Schattenberg et al., 2011; Schoellig et al., 2012; Kushleyev et al., 2012). In the future, multiple vehicle units will also be capable of path planning and interacting within a whole fleet (Barrientos et al., 2011; Cartade et al., 2012). To prevent collisions, or for exploration tasks, the absolute positioning of all the swarm participants at every point in time is very important (Schattenberg et al., 2011). Adapting the approaches for multiple robot motion coordination, autonomous vehicles moving along independent paths will be able to avoid mutual collisions (Siméon et al., 2002). The research team Bry et al. (2012), from the Massachusetts Institute of Technology (MIT) in Cambridge, USA, has already reached a further step in this challenge. They developed algorithms for autonomous control of an indoor GPS-denied UAS and successfully tested an indoor flight in an underground parking lot.

\section{Discussion}

With manually driven, partly automatic, completely autonomous mobile sensor platforms or robots, an increased sensor implementation is possible. Based on the knowledge of stationary industrial robots, operational outdoor sensor platforms and robots emerged in research. Due to constant, structured and predictable indoor working environments, the control and management of industrial robots can be done in an automated way. The implementation with the same safety and accuracy for field tasks is more challenging due to the rough and changing environmental conditions which are changing dynamically and continuously. Variability or heterogeneity in agricultural fields are caused by many natural factors like terrain, soil, vegetation, illumination, visibility and other atmospheric conditions like wind or humidity, which vary in time and space, and are characterized by rapid changes (Bechar and Edan, 2003). These uncertainties make it challenging for sensor data acquisition outdoors and more variables have to be taken into account for sensor calibration and set-up. Factors which might have negative influences on sensor measurements whilst using them on sensing platforms are (1) vibrations due to the type of propulsion, (2) uneven terrain, (3) turbulences in air, (4) noise of the vehicle itself, (5) pollution, dust or particles in the surrounding area, (6) self-shadowing depending on the sun position and sensor height, (7) changes in illumination due to clouds, (8) the distance to the desired measurement object, or (9) the response time of the sensor itself (Agogino et al., 1995; Schilling and Jungius, 1996; Schulz et al., 2012). The energy consumed through the need for torque, for required maintenance of a complex carrying platform, and for staff to run the system, increase the acquisition process costs. Modifications of chassis require permissions and must fulfil certain legal requirements when a system is operated selfpropelled on public roads for easier field changes or transportation, and even more for aerial or autonomous purposes. Nevertheless, higher ground coverage and more repeatable measurements per season with a continuous predefined setup are the reasons why platforms are used at an increasing rate for sensing purposes and data collection in agriculture (Moran et al., 1997; Adamchuk et al., 2004; Keller et al., 2011). The results and approaches of these platform projects can accelerate the way from PF to smart farming (SF), where sensors used for a wide range of agricultural tasks are the goal. Smith (2002) noted in 2002 the term "smart" pertaining to farming. She focused on modern practices for reduction of variable production costs (Goodwin and Mishra, 2004). Stein et al. (2007) stated the necessity of appropriate procedures and support tools to increase time from data to management decisions, even more with a high amount of information as on modern farms. In farming systems, tractor-sensor combinations are still state-of-the-art for data collection and applying tasks. Online sensor approaches are preferred for reacting immediately to variable and heterogeneous field conditions, passing a field, and throughout the whole growing season. Combining larger scaled data from a UAS with the detailed point data from a ground-based vehicle offers a wider range of measurement values within a shorter time gap as well as other relevant information, e.g. from an aerial image. As a high and real-time data resolution is important for field treatments, small multicopter are promising tools to involve them in online data acquisition and application processes. Depending on the requirements of the data acquisition process, precise georeferencing is an important feature to locate measured data exactly, even more for RS, e.g. of a UAS (Bláha et al., 2012). Therefore a correction signal for the GPS device 


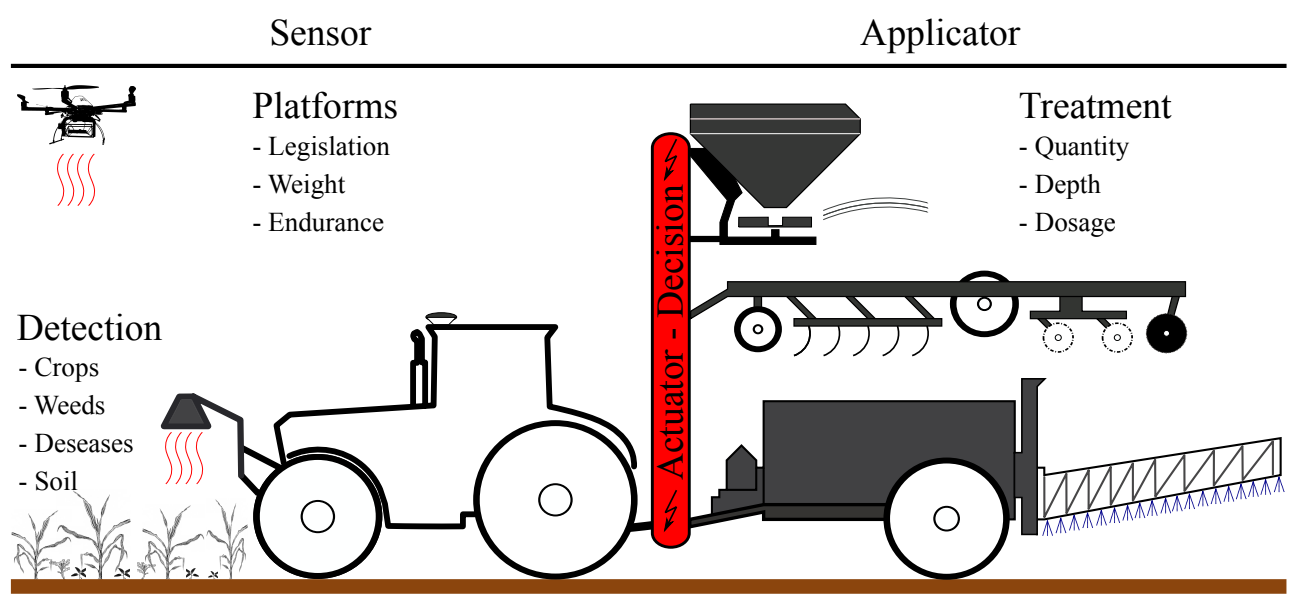

Figure 2. Sensors on aerial and ground platforms for agricultural data acquisition. With the help of the measured data, the actuator controls the system and an agent/applicator carries out the treatment on the field.

on the UAS is necessary. To solve this issue, Rieke et al. (2011) worked in the topic of high spatial precision using RTK accuracy on a UAS system to detect heterogeneity in fields.

As the presence of weeds and grass weeds reduces crop yield significantly, weed management is an important field application. In PF many efforts have already been made and are in development with regards to reducing herbicide application amounts to protect the environment and reduce treatment costs. Ultrasonic systems can be used for weed detection, as well as red and infrared images are used for weed detection and species discrimination. Andújar et al. (2011) described detection success of $81 \%$ in pure stands of grasses and $99 \%$ in pure stands of broad-leaved weeds with an ultrasonic sensor. Recently, Andújar et al. (2012) predicted weed presence in more than $92 \%$ of the cases. Herbicide use has been reduced up to $81 \%$ by using bi-spectral cameras for online detection of weeds and a map-based approach for site-specific spraying (Gerhards and Oebel, 2006). To develop an online weed detection and application system, faster response time for decision and spraying components is required (Weis, 2010). Response time of sensor systems is a main criteria and aimed to be as short as possible (Schulz et al., 2012).

In order to provide a versatile and cost-effective crop monitoring system, Øvergaard et al. (2010) suggested using a lightweight, specifically designed spectral device for a UAS. Instead of expensive sensors, the focus of recent projects have also low-cost consumer devices like digital cameras. With little technical changes inside the device by removing the internal NIR blocking filter, cost-effective quantitative monitoring with good precision is possible. This principle was used in the mid-1990s by Everitt et al. (1995). However, many technical aspects still have to be improved, like the location of spectral bands or the potential for reflectance calibration (Lelong et al., 2008; Hunt Jr. et al., 2010).
As most commercially available sensors are based on the signals of a single sensor, this can lead to misinterpretation of the situation in the field (Zillmann et al., 2006). Samson et al. (2000) showed that nitrogen and sulphur deficiencies have different effects on the laser-induced fluorescence spectral signatures of a field sensor. If these deficiencies were taken into account, by using a sensor capable to detect this effect together with other sensors, management decision would be more reliable and accurate. Mixed sensor signals can be another limitation due to an inexactly defined measurement spot to the canopy. Especially in spectrometry, these signal overlays of plants and soil affect the measurement quality. A solution to this problem is the spectral imaging technology where spectral information for each single pixel is available (Ruckelshausen, 2012). Also for electrical conductivity measurements data of other sources, e.g. of soil moisture, are needed to correctly interpret the values (Dabas et al., 2000; Adamchuk et al., 2004). According to Adamchuk et al. (2010), more robust sensor solutions with higher reliability will become available for agricultural decision-making with the integration of greater quantities of sensor data. Regarding the actual discussed topic smart farming, fusion techniques of a large amount of data sources from mission sensors, as well as navigation sensors will play an important role. Therefore, on the one hand, easy to use decision support systems for the operator or farmer are necessary. On the other hand, standardised system components are required. The ISOBUS machine communication of the agricultural and forestry industry, standardises e.g. connection plugs and data formats. Through this standard, the data output of a sensor can be analysed in the system, taken into account by the actuator and be sent as a decision to the applicator (see Fig. 2). The work for ISOBUS and other standards is ongoing. It will be mandatory for future system solutions, having standardised interchange of internal (machine) and external (e.g. database, UAS) data, as well as of system components. 


\section{Conclusions}

Within the last fifteen years more and more technology from research areas, like the defence sector or sensor engineering, were also implemented into agricultural research and practice. Systems for automatic steering, site-specific crop treatment or data mapping are quite common on modern farms. More powerful electronics, inside of smaller and lighter devices with robust performance, opened the door to new technological approaches in agricultural fields. With these kinds of electronic aids becoming available, there has been greater advancement within the areas of methods and applications. Consequently, the idea of using mobile sensor platforms in agricultural research has become more popular. However, by building up a mobile sensor platform for agricultural purposes, several steps need to be taken into account. The categorisation tree in Fig. 1 provides an overview of relevant modules and information on how mobile sensor platform can be categorised in general.

The main focus of this paper was to clarify, which mobile sensor platforms are already in use or in development, especially in recent agricultural and closely related science projects. It has become evident that there are several platforms available for sea, ground and air usage. Many platforms are currently in use and listed in Table 5 for ground vehicles and Table 6 for unmanned aircraft systems (UAS). A choice can be made between an offline approach (measurement, calculation, and application are separate steps) or an online approach (sensor and direct application) with active or passive sensors. The availability of sensors is huge and can be adapted to the necessary task based on optical, thermal, magnetic, acoustic, mechanical, or chemical measurement methods. Especially mobile sensor platforms, using different sensor systems simultaneously, provide the possibility of comparisons and tests of new sensor approaches, and thus, help to develop suitable sensor systems for precision farming (PF). By implementing multiple sensors on vehicles and in practical application cases, their integration as redundant, complementary or cooperative configuration offers more reliable and more robust decision-making.

Ground platforms and UAS were described that are working either in manual, automatic or autonomous ways. The more advanced the degree of automation is, the more fundamental obstacle detection and collision avoidance are for control processes that can be assured by several sensors. Fusion of the gathered information is an essential part of multidata sources. Information fusion was presented and the architecture models implementing these algorithms are outlined in this manuscript. With this review it was obvious that mobile sensor platforms are able to be applied to mapping, monitoring, scouting and applying tasks in agriculture. The detection of weed or nutrient status in crops are two examples for scouting and monitoring tasks. Further advanced applications still remain at research level.
As the implementation of mobile sensor platforms in agriculture is still at the very beginning, there are several knowledge gaps which need to be solved in the near future. In PF, the goal of growing more and having better output with less input is reflected in practice by the use of sensor technology in applying a more efficient quantity of fertilizers and less chemicals in fields. Sensor-based measurements in agriculture are already used efficiently for site-specific treatments in crops. But the usability of decisions support systems for the farmer still needs to be improved for easier management (see Fig. 2). In agriculture, mainly online sensor solutions for nitrogen application or growing height are developed. However, the causes for variability in the field must be adequately understood before sensor-based decisions can safely be used. Usable online systems for weed detection, crop diseases or water status of the plant are still lacking.

Future applications in agriculture seem to have a strong need for mobile sensor platforms according to the increasing number of agricultural research topics involving ground and aerial vehicles. New sensor approaches with multiple sensors can be developed, compared and tested with these platforms by fusing information for knowledge discovery. More operable systems for the final user with direct decisions made by a task controller in the machine are desired on farms. Mobile sensor platforms are most commonly used in monitoring and scouting applications. Currently, many of these projects are dealing with the detection of soil and plant characteristics (see Table 5). Here, UAS are promising platforms for real-time data equipped e.g. with modified digital cameras.

Sensor technology enables the protection of the environment and the use of resources efficiently, whilst at the same time allowing for even crop development and better harvest qualities. In the future, advanced platforms or robots also need to have the ability to apply, e.g. nutrients or pesticides to a defined management field zone or even to the single plant specifically. Recent research projects dealing with automatic or autonomous robots and swarm technology have been described in this review. Future projects will involve swarm intelligence and swarm behaviour on vehicles or platforms in many application areas.

Depending on the intensity of cultivation and the growing region, there will always be different technology levels of platforms. The market, product quality, environmental concerns of each country, labour costs and human safety will either require middle or high technology level.

Acknowledgements. The authors thank the Carl-ZeissFoundation, Stuttgart, Germany for funding this work within the SENGIS project.

Edited by: U. Schmid

Reviewed by: two anonymous referees 


\section{References}

Acevo-Herrera, R., Aguasca, A., Bosch-Lluis, X., Camps, A., Martínez-Fernández, J., Sánchez-Martín, N., and PérezGutiérrez, C.: Design and First Results of an UAV-Borne L-Band Radiometer for Multiple Monitoring Purposes, Remote Sens., 2, 1662-1679, doi:10.3390/rs2071662, 2010.

Adamchuk, V. I., Hummel, J., Morgan, M., and Upadhyaya, S.: Onthe-go soil sensors for precision agriculture, Comput. Electron. Agric., 44, 71-91, doi:10.1016/j.compag.2004.03.002, 2004.

Adamchuk, V. I., Viscarra Rossel, R. A., Sudduth, K. A., and Schulze Lammers, P.: Sensor Fusion for Precision Agriculture, in: Sensor Fusion - Foundation and Applications, edited by: Thomas, C., InTech, chap. 2, 27-40, 2010.

AeroVironment Inc.: Nano Hummingbird, http://www.avinc.com/ resources/press_release/aerovironment_develops_worlds_first_ fully_operational_life-size_hummingbird, last access: 7 May 2013.

Agogino, A., Goebel, K., and Alag, S.: Intelligent Sensor Validation And Sensor Fusion For Reliability And Safety Enhancement In Vehicle Control, Tech. rep., University of California at Berkley, Berkley, CA, USA, 56 pp., 1995.

Al-Abbas, A., Swain, P., and Baumgardner, M.: Relating Organic Matter and Clay Content to the Multispectral Radiance of Soils, Soil Sci., 114, 477-485, doi:10.1097/00010694197212000-00011, 1972.

Allen, J., Amato, G., Balda, M., Bar, F., Bauer, J., Baumgartner, M., Berglund, E., Boer, J.-F., Carey, L., Clark, K., Clayton, G., Clot, A., Cooke, S. A., Coyne, J., Crowe, W., Davis, D., Dotoli, P., Drai, J., Dumont, P., Eck, C., Egan, P., Eley, M. J., Eravaara, P., Ewers, G., Fernandez, J., Flyer, T., Giacometti, G., Goldfinger, J., Filipe Gonzalez, L., van Gooswilligen, R., Goudou, P., Hejmanowska, B., Hill, P., Hixon, M., Hofmann, F., Homleid, O. V., Kallevig, T., Kobeh Gonzalez, R., Janousek, M., Johnson, C., Jonker, R., Koch, L., Kolev, Z., Koukol, O., Lee, X., Lissone, M., Mäkipaja, S., Mardiné, G., Mason, B., Mahone, B., Manns, E., Martin, F., Matthieu, Y., McCluskey, W., McGroogan, L., McMillan, D., Mejias, L., Mellor, B., Mildenberger, T., Miller, N., Moisio, J., Moreland, J., Morelli, S., Morier, Y., Munaretto, L., Mueller-Nallbach, F., Mulac, B., Osen, P., Palmer, A., Park, W., Prosek, R., Romani, G., Quintana, E., Schultz, D., Seagle, D., Shallies, S., Silva, V., Storvold, R., Tarr, K., ten Buuren, G., Tomasello, F., van de Leijgraaf, R., van Nieuwland, R., Freiherr von Bothmer, B., Walker, J., Walker, R., Wyke, N., Xavier, M., Weis, A., and Zeppenfeldt, F.: UAS Yearbook - The Global Perspective 2011/2012, Blyenburgh \& Co, Paris, France, 9th Edn., 2011.

Andújar, D., Escolà, A., Dorado, J., and Fernández-Quintanilla, C.: Weed discrimination using ultrasonic sensors, Weed Res., 51, 543-547, doi:10.1111/j.1365-3180.2011.00876.x, 2011.

Andújar, D., Weis, M., and Gerhards, R.: An Ultrasonic System for Weed Detection in Cereal Crops, Sensors, 12, 17343-17357, doi:10.3390/s121217343, 2012.

Appel, J. and Nielsen, K.: Applied Multi-Agent Systems Principles to Cooperating Robots in Tomorrow's Agricultural Environment, Ph.D. thesis, University of Southern Denmark, Odense, Denmark, 238 pp., 2005.

Auernhammer, H.: Precision farming - the environmental challenge, Comput. Electron. Agric., 30, 31-43, doi:10.1016/S0168-
1699(00)00153-8, 2001.

Balch, T.: TeamBots ${ }^{\mathrm{TM}} 2.0$ Overview, http://www.teambots.org/, last access: 7 May 2013.

Bäni, D.: Fawn Rescue - Use of a UAV with thermal camera for detection of wild animals, Ph.D. thesis, ETH Zurich, Switzerland, 2011.

Barber, K. S. and Martin, C. E.: Autonomy as DecisionMaking Control, in: Intelligent Agents VII Agent Theories Architectures and Languages, edited by: Castelfranchi, C. and Lespérance, Y., vol. 1986 of Lecture Notes in Comp. Sci., Springer Berlin/Heidelberg, 267-271, doi:10.1007/3-54044631-1_25, 2001.

Barrientos, A., Colorado, J., del Cerro, J., Martinez, A., Rossi, C., Sanz, D., and Valente, J.: Aerial remote sensing in agriculture: A practical approach to area coverage and path planning for fleets of mini aerial robots, J. Field Robot., 28, 667-689, doi:10.1002/rob.20403, 2011.

Bäumker, M., Przybilla, H.-J., and Zurhorst, A.: Enhancement of the Navigation Data Quality of an Autonomous Flying UAV for Use in Photogrammetry, in: Proceedings of the 3rd International Conference on Machine Control \& Guidance, Stuttgart, Germany, 27-29 March 2012, 281-289, 2012.

Bechar, A. and Edan, Y.: Human-robot collaboration for improved target recognition of agricultural robots, Ind. Robot: An Int. J., 30, 432-436, doi:10.1108/01439910310492194, 2003.

Bernardes, T., Moreira, M. A., Adami, M., Giarolla, A., and Rudorff, B. F. T.: Monitoring Biennial Bearing Effect on Coffee Yield Using MODIS Remote Sensing Imagery, Remote Sens., 4, 2492-2509, doi:10.3390/rs4092492, 2012.

Blackmore, S.: UniBots - Agricultural Robotics Portal, http:// www.unibots.com/Agricultural_Robotics_Portal.htm, last access: 7 May 2013.

Blackmore, S. and Griepentrog, H. W.: A future view of Precision Farming, in: Proceedings of the PreAgro Precision Agriculture Conference, Bonn, Germany, 13-15 March 2002, 131-145, 2002.

Blackmore, S., Stout, B., Maohua, W., and Runov, B.: Robotic agriculture - the future of agricultural mechanisation?, in: Proceedings of the 5th European Conference on Precision Agriculture, Uppsala, Sweden, 9-12 June 2005, 621-628, 2005.

Bláha, M., Eisenbeiss, H., Grimm, D., and Limpach, P.: Direct Georeferencing of UAVs, ISPRS - International Archives of the Photogrammetry, Remote Sensing and Spatial Information Sciences, XXXVIII-1/C22, 131-136, doi:10.5194/isprsarchivesXXXVIII-1-C22-131-2011, 2012.

Blanco, J.-L., Moreno, F.-A., and Gonzalez, J.: A collection of outdoor robotic datasets with centimeter-accuracy ground truth, Auton. Robots, 27, 327-351, doi:10.1007/s10514-009-9138-7, 2009.

BMJ: §16 LuftVO (German Air Traffic Regulations) Erlaubnisbedürftige Nutzung des Luftraums, Regulation, BMJ (German Federal Ministry of Justice), Berlin, Germany, 1 pp., http://www.gesetze-im-internet.de/luftvo/_16.html, 2012.

Bossé, E., Roy, J., and Grenier, D.: Data fusion concepts applied to a suite of dissimilar sensors, in: Proceedings of the Canadian Conference on Electrical and Computer Engineering, Calgary, AB, Canada, 26-29 May 1996, 692-695, doi:10.1109/CCECE.1996.548247, 1996. 
Bravo, C., Moshou, D., Oberti, R., West, J., McCartney, A., Bodria, L., and Ramon, H.: Foliar Disease Detection in the Field Using Optical Sensor Fusion, Agr. Eng. Int., 6, 14 pp., 2004.

Bry, A., Bachrach, A., and Roy, N.: State estimation for aggressive flight in GPS-denied environments using onboard sensing, in: Proceedings of the IEEE International Conference on Robotics and Automation (ICRA), St. Paul, MN, USA, 14-18 May, 8 pp., doi:10.1109/ICRA.2012.6225295, 2012.

Bürkle, A., Segor, F., and Kollmann, M.: Towards Autonomous Micro UAV Swarms, J. Intell. Robotic Syst., 61, 339-353, doi:10.1007/s10846-010-9492-x, 2011.

Busemeyer, L., Klose, R., Linz, A., Thiel, M., Tilneac, M., Wunder, E., and Ruckelshausen, A.: Agro-sensor systems for outdoor plant phenotyping platforms in low and high density crop field plots, in: Proceedings of the 68th International Conference on Agricultural Engineering, Braunschweig, Germany, 27-28 October 2010, 213-218, 2010.

CAA: Basic principles of Unmanned Aircraft, Tech. rep., Civil Aviation Authority, London, UK, 1 pp., http://www.caa.co.uk/, 2009.

CAA: CAP 722 Unmanned Aircraft System Operations in UK Airspace - Guidance, UK Civil Aviation Authority, Gatwick, West Sussex, UK, 5 Edn., 2012.

Cartade, P., Lenain, R., Thuilot, B., and Berducat, M.: Formation Control Algorithm for a Fleet of Mobile Robots, in: Proceedings of the 3rd International Conference on Machine Control \& Guidance, Stuttgart, Germany, 27-29 March 2012, 91-100, 2012.

Cepeda, J. S., Chaimowicz, L., and Soto, R.: Exploring Microsoft Robotics Studio as a Mechanism for Service-Oriented Robotics, in: Latin American Robotics Symposium and Intelligent Robotics Meeting, IEEE, 7-12, doi:10.1109/LARS.2010.18, 2010.

Compton, M., Neuhaus, H., Taylor, K., and Parashar, A.: Semantic Sensor Network Ontology, https://marinemetadata.org/ community/teams/ontdevices/ontdevrel, last access: 7 May 2013.

Corwin, D. L. and Lesch, S. M.: Application of Soil Electrical Conductivity to Precision Agriculture, Agron. J., 95, 455-471, 2003.

Côté, C., Brosseau, Y., Létourneau, D., Raïevsky, C., and Michaud, F.: Robotic Software Integration Using MARIE, Int. J. Adv. Robotic Syst., 3, 55-60, 2006.

Crowley, J.: Navigation for an intelligent mobile robot, IEEE J. Robotics Autom., 1, 31-41, doi:10.1109/JRA.1985.1087002, 1985.

Dabas, M., Brisard, A., Tabbagh, J., and Boigontier, D.: Use of a new sub-metric multi-depth soil imaging system (MuCEP), in: Proceedings of the 5th International Conference on Precision Agriculture, Bloomington, MN, USA, 16-19 July 2000, 13 pp., 2000.

Dasarathy, B.: Sensor fusion potential exploitation-innovative architectures and illustrative applications, Proceedings of the IEEE, 85, 24-38, doi:10.1109/5.554206, 1997.

Dasarathy, B. V.: Information Fusion - what, where, why, when, and how?, Inform. Fusion, 2, 75-76, doi:10.1016/S15662535(01)00032-X, 2001.

de Croon, G., de Weerdt, E., de Wagter, C., Remes, B., and Ruijsink, R.: The appearance variation cue for obstacle avoidance, IEEE Trans. Robotics, 28, 529-534, 2012.

d'Oleire Oltmanns, S., Marzolff, I., Peter, K., and Ries, J.: Unmanned Aerial Vehicle (UAV) for Monitoring Soil Erosion in Morocco, Remote Sens., 4, 3390-3416, doi:10.3390/rs4113390,
2012.

Doyle, L., Vellekoop, M. J., and Mlodzianowski, W.: Optifert, http: //www.optifert.eu/, last access: 7 May 2013.

Dunford, R., Michel, K., Gagnage, M., Piégay, H., and Trémelo, M.-L.: Potential and constraints of Unmanned Aerial Vehicle technology for the characterization of Mediterranean riparian forest, Int. J. Remote Sens., 30, 4915-4935, doi:10.1080/01431160903023025, 2009.

Durrant-Whyte, H. and Bailey, T.: Simultaneous localization and mapping: part I, IEEE Robotics Autom. Mag., 13, 99-110, doi:10.1109/MRA.2006.1638022, 2006.

Durrant-Whyte, H. F.: Sensor Models and Multisensor Integration, Int. J. Robot. Res., 7, 97-113, doi:10.1177/027836498800700608, 1988.

Eisenbeiss, H., Kunz, M., and Ingensand, H. (Eds.): Proceedings of the International Conference on Unmanned Aerial Vehicle in Geomatics (UAV-g 2011), International Archives of the Photogrammetry, Remote Sensing and Spatial Information Sciences, Vol. 38-1/C22, ETH Zurich, Zurich, Switzerland, 2011.

Elmenreich, W.: An Introduction to Sensor Fusion, Tech. rep., Vienna University of Technology, Department of Computer Engineering, Vienna, Austria, 28 pp., 2002.

Encyclopaedia Britannica: Automation, http://www.britannica. com/EBchecked/topic/44912/automation, last access: 7 May 2013.

Engelberger, J. F.: Historical Perspective and Role in Automation, in: Handbook of Industrial Robotics, edited by: Nof, S. Y., chap. 1, 3-10, John Wiley \& Sons, Inc., New York, NY, USA, 2nd Edn., 1999.

Evans, M., Anderson, J., and Crysdale, G.: Achieving flexible autonomy in multiagent systems using constraints, Appl. Artif. Intell., 6, 103-126, doi:10.1080/08839519208949944, 1992.

Everitt, J., Escobar, D., Cavazos, I., Noriega, J., and Davis, M.: A three-camera multispectral digital video imaging system, Remote Sens. Environ., 54, 333-337, doi:10.1016/00344257(95)00169-7, 1995.

FAA: Unmanned Aircraft (UAS), http://www.faa.gov/about/ initiatives/uas/uas_faq/, last access: 7 May 2013.

Fender, F., Hanneken, M., Stroth, S. I. D., Linz, A., and Ruckelshausen, A.: Sensor Fusion Meets GPS: Individual Plant Detection, in: Proceedings of the XVI. CIGR World Congress \& AgEng Bonn 2006 \& 64th VDI-MEG International Conference Agricultural Engineering, Bonn, Germany, 3-7 September 2006, 279-280, 2006.

Fischer, D.: Mechanical weed control in organic sugar beets, Ph.D. thesis, University of Hohenheim, Stuttgart, Germany, 174 pp., 2012.

Fraisse, C. W., Sudduth, K. A., and Kitchen, N. R.: Delineation of site-specific management zones by unsupervised classification of topographic attributes and soil electrical conductivity, T. ASAE, 44, 155-166, 2001.

Franke, J., Mewes, T., and Menz, G.: Airborne hyperspectral imaging for the detection of powdery mildew in wheat, in: Proceedings of SPIE 7086, Imaging Spectrometry XIII, 7086, 708609:1708609:10, doi:10.1117/12.795040, 2008.

Frost, A., McMaster, A., Saunders, K., and Lee, S.: The development of a remotely operated vehicle (ROV) for aquaculture, Aquacult. Eng., 15, 461-483, doi:10.1016/S01448609(96)01004-7, 1996. 
García-Pérez, L., García-Alegre, M., Ribeiro, A., and Guinea, D.: An agent of behaviour architecture for unmanned control of a farming vehicle, Comput. Electron. Agric., 60, 39-48, doi:10.1016/j.compag.2007.06.004, 2008.

Geipel, J., Knoth, C., Elsässer, O., and Prinz, T.: DGPS- and INSBased Orthophotogrammetry on Micro UAV Platforms for Precision Farming Services, in: Proceedings of the Geoinformatics 2011 Conference, Münster, Germany, 15-17 June 2011, 174179, 2011.

Gerhards, R. and Oebel, H.: Practical experiences with a system for site-specific weed control in arable crops using real-time image analysis and GPS-controlled patch spraying, Weed Res., 46, 185-193, doi:10.1111/j.1365-3180.2006.00504.x, 2006.

Goodwin, B. K. and Mishra, A. K.: Farming Efficiency and the Determinants of Multiple Job Holding by Farm Operators, Am. J. Agr. Econ., 86, 722-729, doi:10.1111/j.00029092.2004.00614.x, 2004.

Gottlieb, E., Harrigan, R., McDonald, M., Oppel, F., and Xavier, P.: The Umbra Simulation Framework, Tech. rep., Intelligent Systems and Robotics Center Sandia National Laboratories, Albuquerque, NM, USA, 17 pp., doi:10.2172/782709, 2001.

Graeff, S., Link, J., and Claupein, W.: Identification of powdery mildew (Erysiphe graminis sp. tritici) and take-all disease (Gaeumannomyces graminis sp. tritici) in wheat (Triticum aestivum L.) by means of leaf reflectance measurements, Cent. Eur. J. Biol., 1, 275-288, doi:10.2478/s11535-006-0020-8, 2006.

Griepentrog, H. W., Ruckelshausen, A., Jørgensen, R. N., Lund, I., Oerke, E.-C., Gerhards, R., Menz, G., and Sikora, R. A.: Autonomous Systems for Plant Protection, in: Precision Crop Protection - the Challenge and Use of Heterogeneity, Oerke, E.-C., Gerhards, R., Menz, G., and Sikora, R. A. (Eds.), Springer Science+Business Media B.V., Heidelberg, 323-334, doi:10.1007/978-90-481-9277-9, 2010.

Gröll, K., Graeff, S., and Claupein, W.: Use of Vegetation indices to detect plant diseases, in: Proceedings of the 27th GIL Annual Conference, 340, Stuttgart, Germany, 5-7 March 2007, 91-94, 2007.

Grossmann, P.: Multisensor Data Fusion, GEC J. Technol., 15, $27-$ 37, 1998.

Gutjahr, C. and Gerhards, R.: Decision Rules for Site-Specific Weed Management, in: Precision Crop Protection - the Challenge and Use of Heterogeneity, Oerke, E.-C., Gerhards, R., Menz, G., and Sikora, R. A. (Eds.), Springer Science+Business Media B.V., Heidelberg, Germany, 223-239, doi:10.1007/978-90-481-92779_14, 2010.

Haboudane, D., Miller, J. R., Tremblay, N., Zarco-Tejada, P. J., and Dextraze, L.: Integrated narrow-band vegetation indices for prediction of crop chlorophyll content for application to precision agriculture, Remote Sens. Environ., 81, 416-426, doi:10.1016/S0034-4257(02)00018-4, 2002.

Hague, T., Marchant, J., and Tillett, N.: Ground based sensing systems for autonomous agricultural vehicles, Comput. Electron. Agric., 25, 11-28, doi:10.1016/S0168-1699(99)00053-8, 2000.

Hayes-Roth, B.: A blackboard architecture for control, Artif. Intell., 26, 251-321, doi:10.1016/0004-3702(85)90063-3, 1985.

He, B., Zhang, H., Li, C., Zhang, S., Liang, Y., and Yan, T.: Autonomous navigation for autonomous underwater vehicles based on information filters and active sensing., Sensors, 11, 1095810980, doi:10.3390/s111110958, 2011.
Herbst, R. (Eds.): UAS-UL Proceedings, in: Proceedings of the 1st Conference on Autonomously Flying Systems for Sustainable Agriculture (UAS-UL), HU Berlin, Berlin, Germany, 2012.

Hoge, F. E., Swift, R. N., and Yungel, J. K.: Active-passive airborne ocean color measurement. 2: Applications, Appl. Optics, 25, 4857, doi:10.1364/AO.25.000048, 1986.

Hunt Jr., E. R., Hively, W. D., Fujikawa, S. J., Linden, D. S., Daughtry, C. S., and McCarty, G. W.: Acquisition of NIR-Green-Blue Digital Photographs from Unmanned Aircraft for Crop Monitoring, Remote Sens., 2, 290-305, doi:10.3390/rs2010290, 2010.

ICAO: ICAO Cir 328, Unmanned Aircraft Systems (UAS), International Civil Aviation Organization, Montréal, Quebec, Canada, 2011.

IDGA: Unmanned aerial system, http://www.idga.org/glossary/ unmanned-aerial-system/, last access: 7 May 2013.

Jensen, K., Nielsen, S. H., Larsen, M., Bøgild, A., Green, O., and Jørgensen, R. N.: FroboMind - proposing a conceptual architecture for field robots, in: Proceedings of the International Conference of Agricultural Engineering (CIGR-AgEng), 5th Automation Technology for Off-road Equipment Conference (ATOE), Valencia, Spain, 8-12 July 2012, 163-168, 2012.

Jia, Z., Balasuriya, A., and Challa, S.: Autonomous Vehicles Navigation with Visual Target Tracking: Technical Approaches, Algorithms, 1, 153-182, doi:10.3390/a1020153, 2008.

Jonjak, A. K.: Analysis of Site-Specific Adjustment Applied to OnThe-Go Soil Sensing Data for Agronomic Use, Biol. Syst. Eng. - Dissertations, Theses, and Student Research, 2011.

Jørgensen, R. N., Sørensen, C. G., Maagaard, J., Havn, I., Jensen, K., Søgaard, H. T., and Sørensen, L. B.: HortiBot: A System Design of a Robotic Tool Carrier for High-tech Plant Nursing, Agri. Eng. Int.: the CIGR Ejournal, 9, 13 pp., 2007.

Kam, H., Schmittmann, O., and Schulze Lammers, P.: Cropping System for Mechanical Intra-/Inter Row Weeding, in: Proceedings of the 67th International Conference on Agricultural Engineering, 135-140, Hanover, Germany, 6-7 November 2009.

Karaboga, D. and Akay, B.: A survey: algorithms simulating bee swarm intelligence, Artif. Intell. Review, 31, 61-85, doi:10.1007/s10462-009-9127-4, 2009.

Keller, M., Zecha, C., Weis, M., Link, J., Gerhards, R., and Claupein, W.: Competence centre SenGIS - exploring methods for georeferenced multi-sensor data acquisition, storage, handling and analysis, in: Proceedings of the 8th European Conference on Precision Agriculture (ECPA), Prague, Czech Republic, 11-14 July 2011, 491-500, 2011.

Khosla, R.: Precision agriculture: challenges and opportunities in a flat world, in: Proceedings of the 19th World Congress of Soil Science, Soil Solutions for a Changing World, Brisbane, Australia, 1-6 August 2010, 26-28, 2010.

Kittmann, K., Breeman, J., and Schmollgruber, P.: The NACRE Innovative Evaluation Platform and its Navigation \& Control Strategies, in: Proceedings of the SAE 2011 AeroTech Congress \& Exhibition, Toulouse, France, 18-21 October 2011.

Knappenberger, T. and Köller, K.: Spatial assessment of the correlation of seeding depth with emergence and yield of corn, Precis. Agric., 13, 163-180, doi:10.1007/s11119-011-9235-4, 2011.

Konolige, K., Myers, K., Ruspini, E., and Saffiotti, A.: The Saphira architecture: a design for autonomy, J. Exp. Theor. Artif. Intell., 9, 215-235, doi:10.1080/095281397147095, 1997. 
Kushleyev, A., Mellinger, D., and Kumar, V.: Towards A Swarm of Agile Micro Quadrotors, in: Proceedings of the Conference for Robotics Science and Systems VIII, Sydney, Australia, 9-13 July 2012, 8 pp., 2012.

la Cour-Harbo, A.: Publications, http://vbn.aau.dk/en/persons/ pp_b77b18f5-cfd8-413a-99d6-722226da105c/publications. html, last access: 7 May 2013.

Laliberte, A. S. and Rango, A.: Incorporation of texture, intensity, hue, and saturation for rangeland monitoring with unmanned aircraft imagery, in: The International Archives of the Photogrammetry, Remote Sensing, and Spatial Information Sciences, GEOBIA 2008, Vol. XXXVIII-4/, Calgary, Alberta, Canada, 5-8 August 2008.

Lamb, D.: The use of qualitative airborne multispectral imaging for managing agricultural crops - a case study in south-eastern Australia, Aust. J. Exp. Agr., 40, 725-738, 2000.

Langley, R. B.: Innovation: the GPS error budget, GPS World, 8, 51-56, 1997.

Lebourgeois, V., Bégué, A., Labbé, S., Mallavan, B., Prévot, L., and Roux, B.: Can Commercial Digital Cameras Be Used as Multispectral Sensors? A Crop Monitoring Test, Sensors, 8, 73007322, doi:10.3390/s8117300, 2008.

Lee, W., Slaughter, D. C., and Giles, D.: Robotic Weed Control System for Tomatoes, Precis. Agric., 1, 95-113, 1999.

Lelong, C. C. D., Burger, P., Jubelin, G., Roux, B., Labbé, S., and Baret, F.: Assessment of Unmanned Aerial Vehicles Imagery for Quantitative Monitoring of Wheat Crop in Small Plots, Sensors, 8, 3557-3585, doi:10.3390/s8053557, 2008.

Lindström, M., Orebäck, A., and Christensen, H. I.: BERRA: a research architecture for service robots, in: Proceedings of the 2000 IEEE International Conference on Robotics and Automation, IEEE, San Francisco, CA, USA, 24-28 April 2000, 32783283, doi:10.1109/ROBOT.2000.845168, 2000.

Link, J., Zillmann, E., Graeff, S., Batchelor, W., and Claupein, W.: Method for generating site-specific prescription maps via offline technique, in: Mitteilungen der Gesellschaft für Pflanzenbauwissenschaften, Vol. 19, 224-225, Schmidt \& Klaunig KG, Kiel, Germany, Bonn, Germany, 2007.

Link-Dolezal, J., Reidelstürz, P., Graeff, S., and Claupein, W.: Use of a UAV for acquisition of multispectral data in winter wheat, in: Precision Agriculture Reloaded - Informationsgestützte Landwirtschaft, 105-108, Gesellschaft für Informatik (GI), Stuttgart, Germany, 2010.

Link-Dolezal, J., Kittmann, K., Senner, D., and Claupein, W.: Testing a Mini UAS to collect geo-referenced data for agricultural purposes, in: Proceedings of the 3rd International Conference on Machine Control \& Guidance, Stuttgart, Germany, 27-29 March 2012, 224-234, 2012.

López-Granados, F.: Weed detection for site-specific weed management: mapping and real-time approaches, Weed Res., 51, 1-11, doi:10.1111/j.1365-3180.2010.00829.x, 2011.

Luo, R., Yih, C., and Su, K.: Multisensor fusion and integration: : Approaches, applications, and future research directions, IEEE Sens. J., 2, 107-119, 2002.

Maidl, F.-X., Huber, G., and Schächtl, J.: Strategies for site specific nitrogen fertilisation on winter wheat, in: Proceedings of the 7th International Conference on Precision Agriculture, Minneapolis, MN, USA, 25-28 July 2004, 1938-1948, 2004.
Makarenko, A., Brooks, A., and Kaupp, T.: Orca: Components for Robotics, in: Proceedings of the International Conference on Intelligent Robots and Systems (IROS), Workshop on Robotic Standardization, Beijing, China, 9-15 October 2006, 5 pp., 2006.

Marrazzo, W. N., Heinemann, P. H., Crassweller, R. E., and LeBlanc, E.: Electronic nose chemical sensor feasibility study for the differentiation of apple cultivars, Trans. ASAE, 48, 19952002, 2005.

Martinon, V., Fadailli, E. M., Evain, S., and Zecha, C. W.: Multiplex: An innovative optical sensor for diagnosis, mapping and management of nitrogen on wheat, in: Proceedings of the 8th European Conference on Precision Agriculture (ECPA), Prague, Czech Republic, 11-14 July 2011, 547-561, 2011.

Maurer, M.: Carolo-Cup, http://www.carolo-cup.de/, last access: 7 May 2013.

McBratney, A., Whelan, B., Ancev, T., and Bouma, J.: Future Directions of Precision Agriculture, Precis. Agric., 6, 7-23, doi:10.1007/s11119-005-0681-8, 2005.

Merriam-Webster Inc.: Platform, http://www.merriam-webster. com/dictionary/platform, last access: 7 May 2013.

Merz, T. and Chapman, S.: Autonomous unmanned helicopter system for remote sensing missions in unknown environments, in: International Archives of the Photogrammetry, Remote Sensing and Spatial Information Sciences, Conference on Unmanned Aerial Vehicle in Geomatics (UAV-g 2011), Vol. 38-1/C22, 6 pp., Zurich, Switzerland, 14-16 September 2011.

Millonas, M.: Swarms, phase transitions, and collective intelligence, in: Proceedings of the 3rd Conference on Artificial Life, Santa Fe, NM, USA, 15-19 June 1992, 30 pp., 1992.

Montemerlo, M., Roy, N., and Thrun, S.: Perspectives on standardization in mobile robot programming: the carnegie mellon navigation (carmen) toolkit, in: Proceedings of the International Conference on Intelligent Robots and Systems (IROS), IEEE, Las Vegas, NV, USA, 3, 2436-2441, doi:10.1109/IROS.2003.1249235, 2003.

Moore, M. M. and Lu, B.: Autonomous Vehicles for Personal Transport: A Technology Assessment, Social Science Research Network, 13 pp., doi:10.2139/ssrn.1865047, 2011.

Moran, M., Inoue, Y., and Barnes, E.: Opportunities and limitations for image-based remote sensing in precision crop management, Remote Sens. Environ., 61, 319-346, doi:10.1016/S00344257(97)00045-X, 1997.

$\mu$ Drones: Micro drone autonomous navigation for environment sensing, http://www.ist-microdrones.org/, last access: 7 May 2013.

Mzuku, M., Khosla, R., Reich, R., Inman, D., Smith, F., and MacDonald, L.: Spatial Variability of Measured Soil Properties across Site-Specific Management Zones, Soil Sci. Soc. Am. J., 69, 1572-1579, doi:10.2136/sssaj2005.0062, 2005.

Nebot, P., Torres-Sospedra, J., and Martínez, R. J.: A new HLA-based distributed control architecture for agricultural teams of robots in hybrid applications with real and simulated devices or environments, Sensors, 11, 4385-4400, doi:10.3390/s110404385, 2011.

Nielsen, K., Appel, J., and Demazeau, Y.: Applying AI to Cooperating Agricultural Robots, in: Proceedings of the 3rd IFIP Conference on Artificial Intelligence Applications and Innovations (AIAI), Athens, Greece, 7-9 June 2006, 262-270, doi:10.1007/0-387-34224-9_31, 2006. 
Nørremark, M., Griepentrog, H. W., Nielsen, J., and Søgaard, H. T.: Evaluation of an autonomous GPS-based system for intra-row weed control by assessing the tilled area, Precis. Agric., 13, 149162, doi:10.1007/s11119-011-9234-5, 2011.

Orebäck, A.: A Component Framework for Autonomous Mobile Robots, Ph.D. thesis, KTH Royal Institute of Technology, Stockholm, Sweden, 143 pp., 2004.

Orebäck, A. and Christensen, H. I.: Evaluation of Architectures for Mobile Robotics, Auton. Robots, 14, 33-49, 2003.

Osterloh, C., Meyer, B., Amory, A., Pionteck, T., and Maehle, E.: MONSUN II - Towards Autonomous Underwater Swarms for Environmental Monitoring, in: International Conference on Intelligent Robots and Systems (IROS2012), Workshop on Robotics for Environmental Monitoring, Vilamoura, Algarve, Portugal, 7-12 October 2012, 6 pp., 2012.

Øvergaard, S. I., Isaksson, T., Kvaal, K., and Korsaeth, A.: Comparisons of two hand-held, multispectral field radiometers and a hyperspectral airborne imager in terms of predicting spring wheat grain yield and quality by means of powered partial least squares regression, J. NIR Spectrosc., 18, 247-261, doi:10.1255/jnirs.892, 2010.

Pedersen, S. M., Fountas, S., Have, H., and Blackmore, B. S.: Agricultural robots - system analysis and economic feasibility, Precis. Agric., 7, 295-308, doi:10.1007/s11119-006-9014-9, 2006.

Peña-Barragán, J. M., Kelly, M., de Castro, A. I., and LopezGranados, F.: Discrimination of crop rows using object-based approaches in UAV images for early site-specific weed management in maize fields, in: Proceedings of the 1st International Conference on Robotics and Associated High Technologies and Equipment for Agriculture, Pisa, Italy, 19-21 September 2012, 249-254, 2012.

Pfeifer, R. and Scheier, C.: Understanding Intelligence, 3rd Edn., MIT Press, Cambridge, MA, USA, 720 pp., 2001.

Pinter, P. J., Hatfield, J. L., Schepers, J. S., Barnes, E. M., Moran, M. S., Daughtry, C. S. T., and Upchurch, D. R.: Blended remote sensing tools for house management, Photogramm. Eng. Rem. S., 69, 647-664, 2007.

Princeton University: Platform, http://wordnetweb.princeton.edu/ perl/webwn?s=Platform, last access: 7 May 2013.

Quigley, M., Gerkey, B., Conley, K., Faust, J., Foote, T., Leibs, J., Berger, E., Wheeler, R., and Ng, A.: ROS: an open-source Robot Operating System, in: Proceedings of the International Conference on Robotics and Automation (ICRA), Workshop on Open Source Software in Robotics, Kobe, Japan, 12-17 May 2009, 6 pp., 2009.

Rabatel, G., Gorretta, N., and Labbé, S.: Getting simultaneous red and near infrared bands from a single digital camera for plant monitoring applications, in: Proceedings of the International Conference of Agricultural Engineering (CIGR-AgEng), Valencia, Spain, 8-12 July 2012, 6 pp., 2012.

Reid, J. F., Zhang, Q., Noguchi, N., and Dickson, M.: Agricultural automatic guidance research in North America, Comput. Electron. Agric., 25, 155-167, doi:10.1016/S0168-1699(99)00061-7, 2000.

Reyniers, M., Vrindts, E., and De Baerdemaeker, J.: Fine-scaled optical detection of nitrogen stress in grain crops, Opt. Eng., 43, 3119-3129, doi:10.1117/1.1811084, 2004.

RHEA: Robot Fleets for Highly Effective Agriculture and Forestry Management, http://www.rhea-project.eu/, last access: 7 May
2013.

Richharia, M.: Satellite Communication Systems: Design Principles, McGraw-Hill Inc., USA, 2nd Edn., 1999.

Rieke, M., Foerster, T., Geipel, J., and Prinz, T.: High-precision positioning and real-time data processing of uav-systems, in: International Archives of the Photogrammetry, Remote Sensing and Spatial Information Sciences, Conference on Unmanned Aerial Vehicle in Geomatics (UAV-g 2011), Vol. 38-1/C22, 6 pp., Zurich, Switzerland, 14-16 September 2011.

Rothman, P. L. and Denton, R. V.: Fusion or confusion: knowledge or nonsense?, in: Proceedings of SPIE, 1470, 2-12, doi:10.1117/12.44835, 1991.

Ruckelshausen, A.: New sensor developments, in: Proceedings of the 1st Julius-Kühn-Symposium on Sensory in Crop Production, Quedlinburg, Germany, 21 June 2012, 6, 2012.

Ruckelshausen, A., Klose, R., Linz, A., Marquering, J., Thiel, M., and Tölke, S.: Autonomous robots for weed control, in: Proceedings 23rd German Conference on Weed Biology and Weed Control, Stuttgart-Hohenheim, Germany, 7-9 March 2006, 173-180, 2006.

Sainz-Costa, N., Ribeiro, A., Burgos-Artizzu, X. P., Guijarro, M., and Pajares, G.: Mapping wide row crops with video sequences acquired from a tractor moving at treatment speed., Sensors, 11, 7095-109, doi:10.3390/s110707095, 2011.

Samson, G., Tremblay, N., Dudelzak, A., Babichenko, S., Dextraze, L., and Wollring, J.: Nutrient stress of corn plants: early detection and discrimination using a compact multiwavelength fluorescent lidar, in: 20th EARSeL Symposium, 4th EARSeL Workshop Lidar Remote Sensing of Land and Sea, 1, 214-223, Dresden, Germany, 16-17 June 2000.

Saust, F., Wille, J. M., Lichte, B., and Maurer, M.: Autonomous Vehicle Guidance on Braunschweig's inner ring road within the Stadtpilot Project, in: Proceedings of the IEEE Intelligent Vehicles Symposium (IV), IEEE, Baden-Baden, Germany, 5-9 June, 169-174, doi:10.1109/IVS.2011.5940568, 2011.

Schattenberg, J., Lang, T., Becker, M., Batzdorfer, S., Hecker, P., and Andert, F.: Next UAV - Precise relative positioning using low-cost GNSS coupled with INS, optical-flow and cooperative localization methods, in: Proceedings of the 69th International Conference on Agricultural Engineering, Hanover, Germany, 11-12 November 2011, 487-492, 2011.

Schilling, K. and Jungius, C.: Mobile robots for planetary exploration, Control Eng. Pract., 4, 513-524, doi:10.1016/09670661(96)00034-2, 1996.

Schoellig, A. P., Mueller, F. L., and D'Andrea, R.: Optimizationbased iterative learning for precise quadrocopter trajectory tracking, Auton. Robots, 33, 103-127, doi:10.1007/s10514-0129283-2, 2012.

Schuler, H.: Analysis of expediture-to-benefits-ratio of advanced control strategies for chemical processes, Automatisierungstechnische Praxis, 36, 28-40, 1994.

Schulz, V., Gerlach, G., and Röbenack, K.: Compensation method in sensor technology: a system-based description, J. Sens. Sens. Syst., 1, 5-27, doi:10.5194/jsss-1-5-2012, 2012.

Seelan, S. K., Laguette, S., Casady, G. M., and Seielstad, G. A.: Remote sensing applications for precision agriculture: A learning community approach, Remote Sens. Environ., 88, 157-169, doi:10.1016/j.rse.2003.04.007, 2003. 
Shiratsuchi, L., Ferguson, R., Adamchuk, V. I., Shanahan, J., and Slater, G.: Integration of ultrasonic and active canopy sensors to estimate the in-season nitrogen content for corn, in: Proceedings of the 39th North Central Extension-Industry Soil Fertility Conference, Des Moines, IA, USA, 18-19 November 2009, 18-19, 2009.

Sibley, K. J., Astatkie, T., Brewster, G., Struik, P. C., Adsett, J. F., and Pruski, K.: Field-scale validation of an automated soil nitrate extraction and measurement system, Precis. Agric., 10, 162-174, doi:10.1007/s11119-008-9081-1, 2008.

Siméon, T., Leroy, S., and Laumond, J.-P.: Path Coordination for Multiple Mobile Robots: A Resolution-Complete Algorithm, IEEE Trans. Robotics Autom., 18, 42-49, 2002.

Slaughter, D. C., Giles, D., and Downey, D.: Autonomous robotic weed control systems: A review, Comput. Electron. Agric., 61, 63-78, doi:10.1016/j.compag.2007.05.008, 2008.

Slaughter, D. C., Perez-Ruiz, M., Fathallah, F., Upadhyaya, S., Gliever, C. J., and Miller, B.: GPS-Based Intra-Row Weed Control System: Performance and Labor Savings, in: Proceedings of the International Conference of Agricultural Engineering (CIGRAgEng), 5th Automation Technology for Off-road Equipment Conference (ATOE), Valencia, Spain, 8-12 July 2012, 135-139, 2012.

Smith, K.: Does off-farm work hinder "smart" farming?, Agricultural Outlook - United States Economics and Statistics Service, 294, 28-30, 2002.

Smithers, T.: Autonomy in robots and other agents., Brain Cognition, 34, 88-106, doi:10.1006/brcg.1997.0908, 1997.

Søgaard, H. and Olsen, H.: Determination of crop rows by image analysis without segmentation, Comput. Electron. Agric., 38, 141-158, doi:10.1016/S0168-1699(02)00140-0, 2003.

Stein, A., Hoosbeek, M., and Sterk, G.: Space-Time Statistics for Decision Support to Smart Farming, in: Ciba Foundation Symposium 210 - Precision Agriculture: Spatial and Temporal Variability of Environmental Quality, Lake, J. V. and Bock G. R. and Goode J. A. (Eds.), John Wiley \& Sons, Ltd., Chichester, UK, 8, 120-140, doi:10.1002/9780470515419.ch8, 2007.

Steiner, U., Bürling, K., and Oerke, E.-C.: Sensor Use in Plant Protection, Healthy Plants, 60, 131-141, doi:10.1007/s10343-0080194-2, 2008.

Taylor, J. A., McBratney, A., Viscarra Rossel, R. A., Minansy, B., Taylor, H., Whelan, B., and Short, M.: Development of a MultiSensor Platform for Proximal Soil Sensing, in: Proceedings of the 18th World Congress of Soil Science, Philadelphia, PA, USA, 9-15 July 2006, 740a, 2006.

TheUAV: The UAV - Unmanned Aerial Vehicle, http://www.theuav. com/, last access: 7 May 2013.
Tillett, N. D. and Hague, T.: Computer-Vision-based Hoe Guidance for Cereals - an Initial Trial, J. Agric. Eng. Res., 74, 225-236, doi:10.1006/jaer.1999.0458, 1999.

Tobe, F.: The Robot Report, http://www.therobotreport.com/, last access: 7 May 2013.

Tremblay, N., Wang, Z., and Cerovic, Z. G.: Sensing crop nitrogen status with fluorescence indicators. A review, Agron. Sustain. Dev., 32, 451-464, doi:10.1007/s13593-011-0041-1, 2011.

Tucker, C. J.: Remote sensing of leaf water content in the near infrared, Remote Sens. Environ., 10, 23-32, doi:10.1016/00344257(80)90096-6, 1980.

Tucker, C. J. and Sellers, P. J.: Satellite remote sensing of primary production, Int. J. Remote Sens., 7, 1395-1416, doi:10.1080/01431168608948944, 1986.

Turner, D., Lucieer, A., and Watson, C.: An Automated Technique for Generating Georectified Mosaics from Ultra-High Resolution Unmanned Aerial Vehicle (UAV) Imagery, Based on Structure from Motion (SfM) Point Clouds, Remote Sens., 4, 1392-1410, doi:10.3390/rs4051392, 2012.

Watts, A. C., Ambrosia, V. G., and Hinkley, E. A.: Unmanned Aircraft Systems in Remote Sensing and Scientific Research: Classification and Considerations of Use, Remote Sens., 4, 1671-1692, doi:10.3390/rs4061671, 2012.

Weis, M.: An image analysis and classification system for automatic weed species identification in different crops for precision weed management, Ph.D. thesis, University of Hohenheim, Stuttgart, Germany, 126 pp., 2010.

Zarco-Tejada, P. J., González-Dugo, V., and Berni, J.: Fluorescence, temperature and narrow-band indices acquired from a UAV platform for water stress detection using a micro-hyperspectral imager and a thermal camera, Remote Sens. Environ., 117, 322337, doi:10.1016/j.rse.2011.10.007, 2012.

Zhang, C. and Kovacs, J. M.: The application of small unmanned aerial systems for precision agriculture: a review, Precis. Agric., 13, 693-712, doi:10.1007/s11119-012-9274-5, 2012.

Zhang, N., Wang, M., and Wang, N.: Precision agriculture - a worldwide overview, Comput. Electron. Agric., 36, 113-132, doi:10.1016/S0168-1699(02)00096-0, 2002.

Zillmann, E., Graeff, S., Link, J., Batchelor, W. D., and Claupein, W.: Assessment of Cereal Nitrogen Requirements Derived by Optical On-the-Go Sensors on Heterogeneous Soils, Agron. J., 98, 682-690, doi:10.2134/agronj2005.0253, 2006.

Zimmer, U. R.: Autonomous Underwater Vehicles, http://www. transit-port.net/Lists/AUVs.html, last access: 7 May 2013. 